\title{
Aggregate Effects of Gender Gaps in the Labor Market: A Quantitative Estimate*
}

\author{
David Cuberes \\ Marc Teignier \\ Clark University \\ Universitat de Barcelona
}

July 20, 2015

\begin{abstract}
This paper examines the quantitative effects of gender gaps in entrepreneurship and workforce participation. We simulate an occupational choice model with heterogeneous agents in entrepreneurial ability. Gender gaps in entrepreneurship affect negatively both income and aggregate productivity, since they reduce the entrepreneurs' average talent. Specifically, the expected income loss from excluding $5 \%$ of women is $2.5 \%$, while the loss is $10 \%$ if they are all employers. We find that gender gaps cause an average income loss of $15 \%$ in the OECD, $40 \%$ of which is due to entrepreneurship gaps. Extending the model to developing countries, we obtain substantially higher losses, with significant variation across regions.
\end{abstract}

JEL classification numbers: E2, J21, J24, O40.

Keywords: gender inequality, entrepreneurship talent, factor allocation, aggregate productivity, span of control, out-of-necessity self-employment.

*Previously circulated under the titles "Gender Inequality, Factor Allocation, and Aggregate Productivity" and "Gender Gaps in the Labor Market and Aggregate Productivity". Send comments to dcuberes@clarku.edu. 


\section{Introduction}

Although recent decades have witnessed a significant drop in gender gaps in many countries, the prevalence of gender inequality is still high, especially in the developing world. These gaps are apparent in several dimensions, including education, political representation, and bargaining inside the household. In the labor market, women typically receive lower wages, are underrepresented in most occupations, work fewer hours than men and have less access to productive inputs. ${ }^{1}$

One important aspect of gender inequality in the labor market that has not been much studied in the literature is the low presence of women in entrepreneurial activities. The World Bank (2001) estimates that, in developed countries, the average incidence of females among employers is less than 30\%. According to OECD (2014), across the 27 European Union countries, only $25 \%$ of business owners with employees are women, only $3 \%$ of CEOs are women, and the percentage of females in boards is only $18 \% .^{2}$ In OECD countries, the proportion of sole-proprietors enterprises owned by women is between $20 \%$ and $40 \%$. Studies looking at developing countries find much larger gender gaps. Macchiavello et al. (2014), for example, analyze the garment industry in Bangladesh and find that four of every five production workers in this industry are women, while just over one in 20 supervisors is a woman. In their experiment, they show that, after receiving adequate training, women are as likely as men to keep their job but less likely to be tried out or promoted. Everything else equal, a better use of women's potential in the labor market is likely to result in greater macroeconomic efficiency. When there are no friction to agents' labor choices, for example, the most talented people typically organize production carried out by others and, as a result, they can spread their ability advantage over a larger scale. From this point of view, obstacles to women's access to entrepreneurship reduce the average ability of a country's entrepreneurs, affecting negatively the way production is organized in the economy and, hence, reducing its market output. ${ }^{3}$

The objective of this article is to examine the quantitative effects of gender gaps in entrepreneurship and labor force participation on aggregate productivity and income per capita. We first develop an occupational choice model that illustrates the negative impact of gender inequality on resource allocation and, as a result, on aggregate productivity and income

\footnotetext{
${ }^{1}$ See, for instance, Klasen and Lamanna (2009), Olivetti and Petrongolo (2008, 2014), and Blau and Kahn (2007, 2013).

${ }^{2}$ A report by Cranfield University (2014) states that the United Kingdom has made more progress in reducing these gaps than other EU countries: in 2014, $20 \%$ of all directors of UK companies in the FTSE 100 were females, up from $12.5 \%$ in 2010 . The proportion of executive directors in these companies was $7 \%$ up from $5.5 \%$ in 2010 .

${ }^{3}$ Elborgh-Waytek et al. (2013) also argue that gender inequality may have negative macroeconomic effects. Barsh and Yee (2012) claim that the employment of women on an equal basis would allow companies to make a better use of talent.
} 
per capita. Our theoretical framework is an extension of the span-of-control model of Lucas (1978). We add two new elements to his model. First, we consider a third occupation, namely self-employment, on top of employers and workers, as in Gollin (2008). Secondly, we introduce several exogenous frictions that only affect women. In the model, agents are endowed with entrepreneurial talent drawn from a random distribution and choose their occupation based on this talent. While men are unrestricted in their labor market choices, women's choices are limited, which leads of an inefficient allocation of talent across occupations and reduces aggregate productivity as well as income per capita.

Quantitatively, the model predicts that if all women were excluded from entrepreneurship, income per capita would fall by $10 \%$ in the short run, due to the fall in the average talent of entrepreneurs. In the long run, when the capital stock is adjusted to the new productivity level, income per capita would fall by $11 \%$. If all women were excluded from the labor force, on the other hand, output per capita would fall by almost $47 \%$ in the short run, when the capital stock is fixed, and by $50 \%$ in the long run, when capital per worker is readjusted. It is worth noting that in the model we abstract from the decision to participate in the labor market, i.e. we assume that all agents work in some occupation unless they are not "allowed" to do so. Henceforth, our exercise only calculates market output losses, since in reality women not participating in the labor market are likely to generate some production in the household sector. We omit household production in the model to keep the analysis as simple as possible, but also because of the lack of data. ${ }^{4}$

In the cross-country analysis, we use the model to quantify the effects of the existing labor market gender gaps in a large sample of both developed and developing economies. The benchmark model prediction for the sample of OECD countries is an average income loss of $15 \%$ due to entrepreneurship and participation gender gaps, almost $40 \%$ of which is due to due to gender gaps in entrepreneurship. The model is then extended to incorporate out-of-necessity entrepreneurs, i.e. agents who choose self-employment as their occupation because they have no better job choices. We use this extended version of the model to quantify the effects of the gender gaps in a sample of developing countries, for which it has been documented that self-employment (and out-of-necessity self-employment) is much more prevalent than in rich countries. ${ }^{5}$ The model with out-of-necessity self-employed predicts larger average income losses for the sample of developing countries, with significant variation across geographical regions. In the Middle East and North Africa, theaverage income loss due to gender gaps is almost $38 \%$, about a fifth of which is due to the occupational gender gaps, while in Central Asia the average income loss is about 10\%, with $70 \%$ of the loss generated

\footnotetext{
${ }^{4}$ In what follows we will refer to "restrictions" to women in the labor market, although, once again, we do not know with certainty to what extent these restrictions reflect women's optimal choices.

${ }^{5}$ See the Global Entrepreneurship Monitor survey (Brush et al. (2011), www.gemconsortium.org, and Poschke (2013) for a detailed characterization of this type of entrepreneurs.
} 
by the occupational gender gaps. Merging the two samples, we find that there is an inverse- $\mathrm{U}$ relationship between the level of development of a country and its income losses caused by all the gender gaps - entrepreneurship and labor force participation-, while there is a negative relationship between the development level and the income losses caused only by gender gaps in entrepreneurship. These results are consistent with the observed U-shaped relationship between development and female labor force participation. ${ }^{6}$

The origins of these labor market frictions could be very diverse and, in this paper, we do not aim at identifying whether they are due to pure discrimination or they reflect women's optimal choices taking into account their alternatives. In 2010, the OECD launched its Gender Initiative to analyze specific barriers that women face in the labor market, as well as to implement policies that promote gender equality in OECD countries and beyond (OECD 2012, 2014). ${ }^{7}$ The barriers identified in their study can broadly be classified in different categories. First, women are often less likely than men to borrow money in order to finance a business (Eurostat, 2008). ${ }^{8}$ Second, informational or cultural factors may also create barriers for women who wish to become entrepreneurs. For example, shareholders are less likely to appoint women as managers due to lack of data on women's performance as entrepreneurs. Similarly, young women and women out of the labor force often lack accurate information about entrepreneurship as a viable and attractive career for them. Third, women's preferences for part-time work and a better work-like balance, in combination with an inflexible labor market, lead women to run smaller firms and earn less than their male counterparts, which could partly explain why the labor force participation of women is below that of men in most countries. ${ }^{9}$ Fourth, women often seem to lack the necessary confidence in their skills to become entrepreneurs. ${ }^{10}$ Moreover, as a result of all the previous barriers, women tend to have less experience than men when they start up a business, which may explain their lower earnings as entrepreneurs. One additional natural reason why women may be underrepresented in the labor market is the existence of gender gaps in education for young women. In recent decades, however, education gender gaps have substantially shrinked in most countries, as shown in Becker et al. (2010), which documents an unprecedented increase in higher education in the last 40 years all over the world, especially for women. Their study shows that, nowadays,

\footnotetext{
${ }^{6}$ See, for instance, Goldin (1995).

${ }^{7}$ See also www.oecd.org/gender/data.

${ }^{8}$ According to Cole and Mehran (2009), women in the United States are more likely to be discouraged to apply for loans for fear of rejection, although there is some evidence showing that, once they do so, they do not have a higher rejection rate than their men counterpart.

${ }^{9} \mathrm{~A}$ related issue is that, in many countries, government policies tend to focus on helping start-ups and small firms. While this may indeed help women to run their own firms, it makes them less likely to create relatively large firms.

${ }^{10}$ Coleman and Robb (2012) claim that this may in part be explained by women's lack of familiarity with finance and accounting practices.
} 
in most high-income countries and in many lower-income ones, there are indeed more women than men that complete tertiary education. Parro (2012) examines the evolution of the gender gap in education in a large sample of developed and developing countries between 1950 and 2005. He finds that gender inequality in education increased between 1950 and 1975 and decreased between 1975 and 2005. Using long-run data (1800-2010), Morrison and Murtin (2009) construct a new database on historical educational attainment with a sample of 74 countries for the period 1870-2010 and concludes that educational attainment accelerated in the second half of the twentieth century and that there has been some convergence in educational attainment in a sample of developed countries. In terms of gender, they find that in most Asian and African countries, the educational takeoff has closed the gender gap. Only sub-Saharan Africa and India currently lag behind other countries in terms of gender gaps between female and male education. In view of our analysis, one would expect that these improvements should have translated into less gender gaps in the labor market. ${ }^{11}$

The remainder of the article is organized as follows. In Section 2, we briefly discuss the existing literature linking labor gender inequality and economic growth, with an emphasis on papers most closely related to our work. The benchmark theoretical model is presented in Section 3. The numerical simulations and the cross-country results for the OECD sample are described in Section 4. Section 5 presents the extended model for the developing countries and shows the simulation results for the non-OECD sample. Finally, Section 6 concludes.

\section{Literature review}

The empirical literature on the relationship between economic growth and gender inequality is quite extensive. ${ }^{12}$ This literature has reached some consensus on the fact that there is a positive effect of increases in income per capita on gender equality and, more relevant to our paper, a negative effect of gender inequality on economic growth. Some studies show a negative effect of gaps in the labor force participation on a country's economic performance (Klasen and Lamanna, 2009; Thévenon et al., 2012, ILO, 2014). More commonly, though, gender gaps in education have been emphasized as a growth deterrent (Barro and Lee, 1993; Tzannatos, 1999; Dollar and Gatti, 1999; Klasen, 2002; Barro and Sala-i-Martin, 2003; AbuGhaida and Klasen, 2004; Klasen and Lamanna, 2009; Thévenon et al., 2012). These gaps may have a direct effect on growth but they also operate through the labor market channels

\footnotetext{
${ }^{11}$ In spite of the fact that gender differences in education have narrowed substantially in recent decades, girls are still often subject to education biases that make them less inclined to study fields in which individuals are more likely to eventually become entrepreneurs. The OECD (2013), for instance, reports that women have a higher probability to obtain degrees in health and humanities, but they are underrepresented in the so-called STEM fields of study (Science, Technology, Engineering, and Mathematics).

12 See, for instance, Goldin (1990), Dollar and Gatti (1999), Tzannatos (1999), or Klasen (2002). Cuberes and Teignier (2014) provide a comprehensive review of the empirical and theoretical literature on this topic.
} 
that we study in this paper. In particular, as explained above, less educated women, or biases in women's education, can lead to lower female labor force participation and women being underrepresented in entrepreneurship.

In the theoretical literature, several studies focus on explaining the effects of economic growth on different gender gaps, for example, Becker and Lewis (1973), Galor and Weil (1996), Greenwood et al. (2005), Doepke and Tertilt (2009), Fernandez (2009) and Ngai and Petrongolo (2013). Other papers have focused on the reverse effect, i.e. the impact of gender inequality on growth. These theories are, in most cases, based on the fertility and children's human capital channels, as in Galor and Weil (1996), and Lagerlöf (2003). ${ }^{13}$ Galor and Weil (1996), for example, argue that an increase in women's relative wage increases the cost of raising children, which lowers population growth, increases children's education levels and leads to higher labor productivity and growth. Our paper differentiates from these theoretical articles in two directions: first, we calibrate and simulate our theoretical framework in order to be able to produce reasonable estimates of the costs associated to specific gender gaps. Second, we focus on a relatively ignored mechanism through which gender inequality reduces aggregate productivity, namely, the talent pool channel.

With respect to the first point, Cavalcanti and Tavares (2011) construct a growth model based on Galor and Weil (1996) in which there is exogenous wage discrimination against women. When they calibrate their model using U.S. data, they find very large effects associated with these wage gaps: a 50 percent increase in the gender wage gap in their model leads to a decrease in income per capita of a quarter of the original output. Their results also suggest that a large fraction of the actual difference in output per capita between the U.S. and other countries is indeed generated by the presence of gender inequality in wages. We depart from this paper in that our focus is on the misallocation of talent and resources caused by gender inequality.

With respect to the second point, Esteve-Volart (2009) also develops a model of occupational choice and talent heterogeneity. Her paper finds that labor market discrimination leads to lower average entrepreneurial talent and slower female human capital accumulation which, in turn, has a negative impact on technology adoption, innovation and economic growth. The model, however, is used to derive qualitative results but not to carry out numerical exercises.

To our knowledge, the only existing paper that incorporates a quantitative analysis and considers the talent pool channel is Hsieh et al. (2013). Their paper uses a Roy model to estimate the effect of the changing occupational allocation of white women, black men, and black women between 1960 and 2008 on U.S. economic growth and finds that the improved allocation of talent during this period accounts for 17 to 20 percent of growth. Our paper

\footnotetext{
${ }^{13}$ Lagerlöf (2006) calibrates the Galor-Weil model but does not provide a quantitative estimate of the productivity costs associated with a decrease in gender inequality.
} 
differs from theirs in several dimensions. First, we explicitly add self-employment as a possible occupation in the model, which is particularly important to model the behavior of developing countries. Second, we study the effects of gender inequality in the labor market in a large sample of countries, rather than just focusing in the U.S economy. Finally, our theoretical framework is substantially different from theirs in that we emphasize, although, in a static framework, the span-of-control element of agents who run firms. ${ }^{14}$

\section{Benchmark model}

In this section, we present a general equilibrium occupational choice model where agents are endowed with a random entrepreneurship skill that determines their optimal occupation. The model is based on the span-of-control framework in Lucas (1978), with the extension of selfemployment as a possible occupational choice. In the benchmark model, agents choose to work as either employers, self-employed, or workers, while in the extended model presented in Section 5 we introduce the possibility of having the so-called out-of-necessity self-employed, in line with the literature claiming that in developing countries self-employment is the only possible alternative for some agents.

\subsection{Model setup}

The economy we consider has a continuum of agents indexed by their entrepreneurial talent $x$, drawn from a cumulative distribution $\Gamma$ that takes values between $B$ and $\infty$. We assume the economy is closed and that it has a workforce of size $N$ and $K$ units of capital. Labor and capital are inelastically supplied in the market by consumers, in exchange for a wage rate $w$ and a capital rental rate $r$ respectively. These inputs are then combined by firms to produce an homogeneous good. Agents decide to become either firm workers, who earn the equilibrium wage rate $w$ - which we assume to be independent of their entrepreneurial talent-, or entrepreneurs, who earn the profits generated by the firm they manage. ${ }^{15}$

An agent with entrepreneurial talent or productivity level $x$ who chooses to become an employer and hires $n(x)$ units of labor and $k(x)$ units of capital produces $y(x)$ units of output and earns profits $\pi(x)=y(x)-r k(x)-w n(x)$, where the price of the homogeneous good is

\footnotetext{
${ }^{14}$ Our paper also relates to several recent papers that use the span-of-control model of Lucas (1978) to study the effects of financial frictions and other cross-country differences on the misallocation of resources and productivity. See, for example, Amaral and Quintin (2010), Antunes et al. (2008), Bhattacharya et al. (2013), Buera et al. (2011), Buera and Shin (2013) and Erosa et al. (2010).

${ }^{15}$ In what follows we will refer to an entrepreneur as someone who works as either an employer or a selfemployed.
} 
normalized to one. As in Lucas (1978) and Buera and Shin (2011), the production function is given by

$$
y(x)=x\left(k(x)^{\alpha} n(x)^{1-\alpha}\right)^{\eta},
$$

where $\alpha \in(0,1)$ and $\eta \in(0,1)$. The parameter $\eta$ measures the span of control of entrepreneurs and, since it is smaller than one, the entrepreneurial technology involves an element of diminishing returns. On the other hand, an agent with talent $x$ who chooses to become selfemployed uses the amount of capital $\tilde{k}(x)$, produces $\tilde{y}(x)$ units of output and earns profits $\tilde{\pi}(x)=\tilde{y}(x)-r \tilde{k}(x)$. The technology he or she operates is

$$
\tilde{y}(x)=\tau x \tilde{k}(x)^{\alpha \eta}
$$

where $\tau$ is the self-employed productivity parameter. ${ }^{16}$ One interpretation of this parameter is that self-employed workers have to spend a fraction of their time on management tasks, which would imply that $\tau$ is equal to the fraction of time available for work to the power $(1-\alpha) \eta$. As explained below, we estimate this parameter to match the average fraction of self-employed in the data.

\subsection{Agents' optimization}

\subsubsection{Employers}

Employers choose the units of labor and capital they hire in order to maximize their current profits $\pi$. The optimal number of workers and capital stock, $n(x)$ and $k(x)$ respectively, depend positively on the productivity level $x$, as equations (3) and (4) show:

$$
\begin{aligned}
& n(x)=\left[x \eta(1-\alpha)\left(\frac{\alpha}{1-\alpha}\right)^{\alpha \eta} \frac{w^{\alpha \eta-1}}{r^{\alpha \eta}}\right]^{1 /(1-\eta)}, \\
& k(x)=\left[x \eta \alpha\left(\frac{1-\alpha}{\alpha}\right)^{\eta(1-\alpha)} \frac{r^{\eta(1-\alpha)-1}}{w^{\eta(1-\alpha)}}\right]^{1 /(1-\eta)} .
\end{aligned}
$$

\footnotetext{
${ }^{16}$ The consumption good produced by the self-employed and the capital they use is the same as the one in the employers' problem. However, it is convenient to denote them $\tilde{y}$ and $\tilde{k}$ to clarify the exposition.
} 


\subsubsection{Self-employed}

When we solve for the problem of a self-employed agent with talent $x$ who wishes to maximize his or her profits, we find

$$
\tilde{k}(x)=\left(\frac{\tau x \alpha \eta}{r}\right)^{\frac{1}{1-\alpha \eta}} .
$$

\subsubsection{Occupational choice}

Figure (1) displays the shape of the profit functions of employers $\left(\pi_{e}(x)\right)$ and self-employed $\left(\pi_{s}(x)\right)$ along with wage earned by workers as a function of talent $x .{ }^{17}$ The figure also shows the relevant talent cutoffs for the occupational choices Here we present the equations that define these thresholds: the first one, $z_{1}$, defines the earnings such that agents are indifferent between becoming workers or self-employed and it is given by

$$
w=\tau z_{1} \tilde{k}\left(z_{1}\right)^{\alpha \eta}-r \tilde{k}\left(z_{1}\right) .
$$

If $x \leq z_{1}$ agents choose to become workers, while if $x>z_{1}$ they become self-employed or employers. The second cutoff, $z_{2}$, determines the choice between being a self-employed or an employer and it is given by

$$
\tau z_{2} \tilde{k}\left(z_{2}\right)^{\alpha \eta}-r \tilde{k}\left(z_{2}\right)=z_{2} x\left(k\left(z_{2}\right)^{\alpha} n\left(z_{2}\right)^{1-\alpha}\right)^{\eta}-r k\left(z_{2}\right)-w n\left(z_{2}\right)
$$

so that if $x>z_{2}$ an agent wants to become an employer.

\subsection{Female labor market frictions}

Our model assumes that men and women are identical in all dimensions except that women face several exogenous restrictions on their occupational choices. The first constraint we impose is that only a fraction $\mu$ of them can freely choose their occupation, while a fraction $1-\mu$ are excluded from employership. Out of the latter group of women, a fraction $\mu_{o}$ have the possibility of becoming self-employed, while a fraction $1-\mu_{o}$ are also excluded from self-employment. As a result, a fraction $(1-\mu)\left(1-\mu_{o}\right)$ of women are shut out from entrepreneurship, i.e. both employership and self-employment, and can only become workers. ${ }^{18}$

\footnotetext{
${ }^{17}$ In order to construct this figure we are implicitly using values for the parameters $\tau, \alpha$, and $\eta$, such that the three occupations are chosen in equilibrium.

${ }^{18}$ Figure (5) in Appendix A shows the optimal occupation choices of women given the frictions they face.
} 
Figure 1: The occupational map

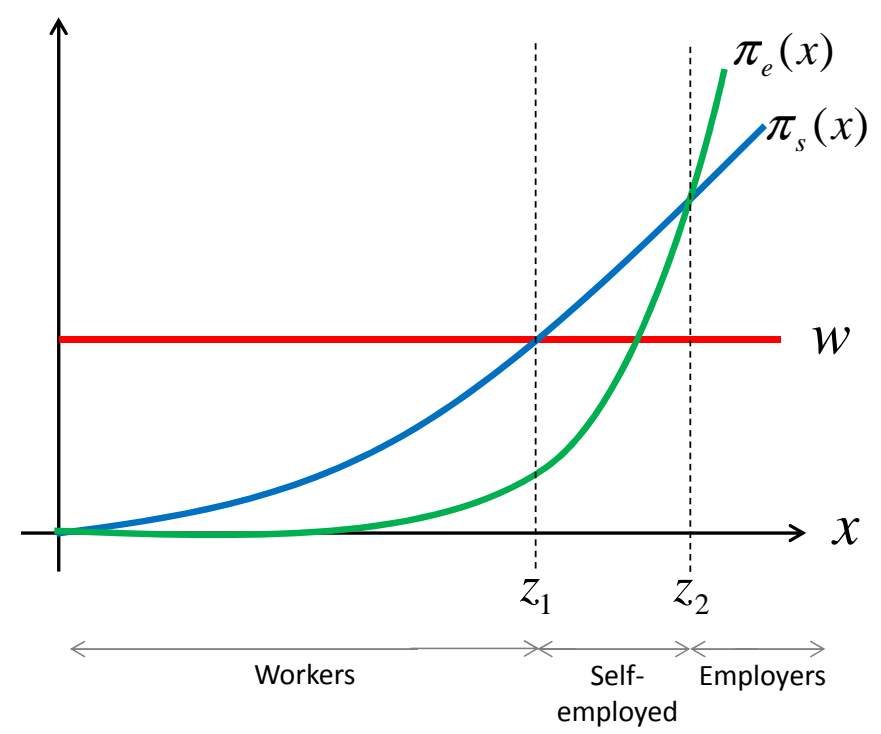

Note that, in this setup, we are not allowing for the possibility of women being excluded from self-employment but not from employership, since we think that whichever are the barriers women face to become self-employed, they should apply even more strongly to become an employer. ${ }^{19}$

Finally, the third friction we introduce is that only a fraction $\lambda$ of women are allowed to participate in the labor market, while a fraction $(1-\lambda)$ of randomly selected women are excluded from all the possible occupations in the labor market. ${ }^{20}$ Again, this friction may reflect discrimination, or other supply factors, but it might also reflect differences in optimal choices of women, or other demand factors. Since our model does not incorporate a household sector, women who do not participate in the labor market produce zero output. Because of this, the income loss due to the $\lambda$ gender gap estimated by our model is actually a market output loss, which is likely to be larger than the total output loss because of the potential production taking place inside the household when women do not participate in the labor market. $^{21}$

Because of the way we introduced these gender gaps into model, all women face the same probability of being excluded from participation and entrepreneurship. This would be the right modeling choice if some women were banned from entrepreneurship or work due to pure

\footnotetext{
${ }^{19}$ In terms of the parameters of the model, if $\mu=1$, then the value of $\mu_{o}$ does not affect the occupational choices of women.

${ }^{20}$ We say that women excluded from the labor force are randomly selected because their talent is drawn from the same distribution as the rest of the population.

${ }^{21}$ To the extent that entrepreneurship gaps affect negatively the labor market participation return of women, a model with household production and endogenous female participation is likely to predict larger output losses due to the introduction of $\mu$ and $\mu_{o}$ gender gaps.
} 
discrimination, if some of them did not have access to education or credit, if some of them had a strong preference for childcare or other forms of home production, or if some lacked the accurate information about entrepreneurship options. Admittedly, the aggregate impact would be larger if more talented women were less likely to be excluded, which would be the case if these distortions affected women's earnings in the form of a fixed cost or a wedge. It could also be the case, however, that more talented women were more likely to get excluded, which would be the case if, for example, they had a higher propensity to marry richer men and, as a result, they were also more likely not to participate in the labor market or to choose part-time work. ${ }^{22}$

\subsection{Competitive Equilibrium}

We assume that women represent half of the population in the economy and that there is no unemployment. Moreover, any agent in the economy can potentially participate in the labor market, except for the restrictions on women described above. Under these assumptions, in equilibrium, the total demand of capital by employers and self-employed must be equal to the aggregate capital endowment (in per capita terms) $k$ :

$$
\begin{aligned}
k & =\frac{1}{2}\left[\int_{z_{2}}^{\infty} k(x) d \Gamma(x)+\int_{z_{1}}^{z_{2}} \tilde{k}(x) d \Gamma(x)\right] \\
& +\frac{\lambda}{2}\left[\mu \int_{z_{2}}^{\infty} k(x) d \Gamma(x)+\left(\mu+(1-\mu) \mu_{0}\right) \int_{z_{1}}^{z_{2}} \tilde{k}(x) d \Gamma(x)+(1-\mu) \mu_{0} \int_{z_{2}}^{\infty} \tilde{k}(x) d \Gamma(x)\right],
\end{aligned}
$$

where the first bracket represents the demand for capital by male entrepreneurs and the second one is the demand for capital by female entrepreneurs, which has three components, each of them multiplied by the fraction of women in the labor force, $\frac{\lambda}{2}$. The first one represents the capital demand by female employers, i.e. those with enough ability to be employers and who are allowed to be so, while the second and third terms represent the demand by female selfemployed; the second term shows the demand for capital by women who have the right ability to be self-employed and are allowed to work as such, and the third term shows the demand from women who become self-employed because they are excluded from employership. ${ }^{23}$

Similarly, in the labor market, the total demand of workers must also be equal to its total

\footnotetext{
${ }^{22}$ Note, however, that by assuming perfect substitution between male and female labor and management we could be biasing downwards the estimated effects of gender gaps if women had comparative advantage in different sectors than men or if they provided a different type of labor.

${ }^{23}$ The functions $k(\cdot)$ and $\widetilde{k}(\cdot)$ are defined in equations (4) and (5).
} 
supply:

$$
\begin{array}{r}
\frac{1}{2}\left[\int_{z_{2}}^{\infty} n(x) d \Gamma(x)\right]+\frac{\lambda}{2} \mu\left[\int_{z_{2}}^{\infty} n(x) d \Gamma(x)\right]= \\
\frac{1}{2} \Gamma\left(z_{1}\right)+\frac{\lambda}{2}\left[\Gamma\left(z_{1}\right)+(1-\mu)\left(1-\mu_{0}\right)\left(1-\Gamma\left(z_{1}\right)\right)\right]
\end{array}
$$

where the upper terms represent the total labor demand and the lower ones the total labor supply. The first term is the labor demand by male employers and the second one corresponds to the labor demand by female employers, i.e. those women with enough ability to be employers who are allowed to participate in the labor market and to choose their occupation freely. The first term of the labor supply shows the fraction of men who choose to become workers, while the second one shows the fraction of female workers. The latter is composed by the fraction of females who want to be workers as well as the fraction of females who have enough ability to be employers or self-employed but are excluded from both occupations. For these group of women, the only option is to become workers. $^{24}$

In this economy, aggregate production per capita, which is the sum of output by male employers and self-employed, as well as output by female employers and female self-employed:

$$
\begin{array}{r}
y \equiv \frac{Y}{N}=\frac{1}{2}\left[\int_{z_{2}}^{\infty} y(x) d \Gamma(x)+\int_{z_{1}}^{z_{2}} \tilde{y}(x) d \Gamma(x)\right]+ \\
\frac{\lambda}{2}\left[\mu \int_{z_{2}}^{\infty} y(x) d \Gamma(x)+\mu \int_{z_{1}}^{z_{2}} \tilde{y}(x) d \Gamma(x)+(1-\mu) \mu_{0} \int_{z_{1}}^{\infty} \tilde{y}(x) d \Gamma(x)\right]
\end{array}
$$

where $y(x)$ and $\tilde{y}(x)$ are defined in equations (1) and (2), respectively.

A competitive equilibrium in this economy is a pair of cutoff levels $\left(z_{1}, z_{2}\right)$, a set of quantities $[n(x), k(x), \tilde{k}(x)], \forall x$, and prices $(w, r)$ such that equations (3) - (9) are satisfied; that is agents choose their occupation optimally, entrepreneurs choose the amount of capital and labor to maximize their profits, and all markets clear.

\subsection{Comparative statics}

In this subsection we show qualitatively how the agents' occupational choice are affected by exogenous changes in the two entrepreneurship gender gaps, namely the fraction of women who are excluded from employership $(1-\mu)$ and the fraction of those women who are also

\footnotetext{
${ }^{24}$ The function $n(\cdot)$ is defined in equation (3).
} 
Figure 2: Qualitative effects of $\mu$ and $\mu_{o}-$ gaps

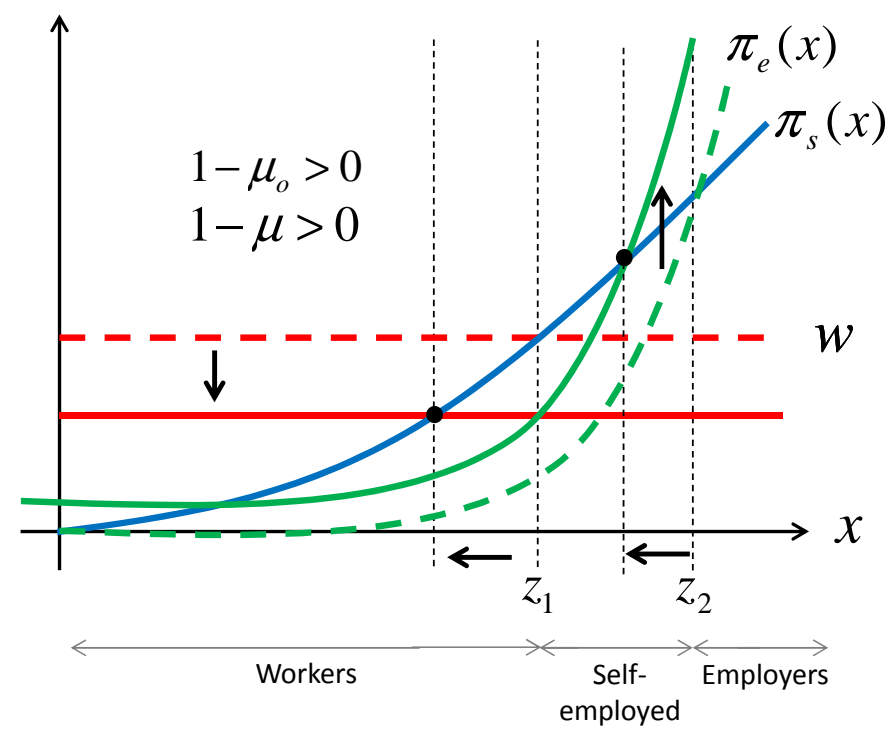

"excluded" from self-employment $\left(1-\mu_{0}\right)$. Figure $(2)$ shows the change in the talent thresholds $\left(z_{1}, z_{2}\right)$ when $(1-\mu)$ and $\left(1-\mu_{0}\right)$ become positive.

\subsubsection{An increase in the employership gender gap $(\downarrow \mu)$}

A decrease in $\mu$ initially generates a decline in the number of employers and hence a decrease in the labor demand and the equilibrium wage, which decreases the cutoff $z_{1}$. Everything else equal, this results in an increase in profits for the remaining employers, which reduces also the cutoff $z_{2}$. The effect on the demand for capital is ambiguous since the demand from employers declines but that of the self-employed increases. If the demand for capital actually decreases, the cost of renting capital goes down, so both self-employed and employers' profits increase and, hence, both cutoffs $z_{1}$ and $z_{2}$ decrease further.

\subsubsection{An increase in self-employment gender gaps $\left(\downarrow \mu_{0}\right)$}

A decrease in $\mu_{0}$ (given $\mu<1$ ) generates a decline in the number of self-employed and hence an increase in the labor supply, which in turn drives wages down. As in the previous case, this has a direct negative effect on the cutoff $z_{1}$ as well as an indirect negative effect on the cutoff $z_{2}$, through its effect on the employers' profit function. As before, whether the demand for capital increases or decreases is a quantitative question since there is a negative effect from the drop in self-employed and a positive one from the rise in employers.

\section{Benchmark model numerical results}

In this section, we simulate the benchmark model to calculate the income effects of the gender gaps in the labor market discussed in the previous section. We first describe the 
Table 1: Parameter values

\begin{tabular}{ccc}
\hline Parameter & Value & Explanation \\
\hline \hline$B$ & 1 & Normalization \\
$\eta$ & 0.79 & From Buera and Shin $(2011)$ \\
$\alpha$ & 0.114 & To match capital share: $\alpha \eta+(1-\eta)=0.3$ \\
$\rho$ & 6.5 & To match employers' share OECD countries \\
$\tau$ & 0.7 & To match self-employed share OECD countries \\
\hline
\end{tabular}

parametrization of the model and calculate the maximum possible effects of these gaps. Then we estimate the gender gaps and quantify their effects using data from OECD countries. In Section 5 we extend the model to make it more suitable for developing countries, and we then use data from non-OECD countries to quantify effects of the gender gaps on these countries.

\subsection{Skill distribution}

To simulate the model, we use a Pareto function for the talent distribution, as in Lucas (1978) and Buera et al. (2011). In particular, the cumulative distribution of talent is given by

$$
\Gamma(x)=1-B^{\rho} x^{-\rho}, x \geq 0,
$$

where $\rho, B>0$.

\subsection{Model Parametrization}

Table 1 shows the parameter values used in the model simulations. The parameter $B$ of the talent distribution is normalized to 1 , while the parameter $\eta$ is taken from Buera and Shin (2011). ${ }^{25}$ The capital-output elasticity parameter $\alpha$ is set to 0.114 in order to match the $30 \%$ capital income share observed in the U.S. data. Since entrepreneurs' profits are considered capital income, we set $\alpha \eta+(1-\eta)$ equal to $30 \%$ as in Buera and Shin (2011). The parameter $\rho$ of the talent distribution is set to 6.5 to minimize the distance between the actual and the predicted fraction of employers in the OECD countries, which is $4.5 \%$ on average. Similarly, the self-employed relative productivity parameter $\tau$ is chosen to match the fraction of self-employed workers in the OECD countries, which is $10.8 \%$ on average.

The cross-country dispersion in the share of employers and self-employed workers is not negligible, with 10th-to-90th interpercentile ranges of 2.3 and 3.17 respectively. This dispersion can obviously not be generated by the parametrization of $\rho$ and $\tau$. As explained in subsection 4.4 , however, the gender gaps $\left(\mu, \mu_{o}, \lambda\right)$ are country specific and they do generate

\footnotetext{
${ }^{25}$ Buera and Shin (2011) choose $\eta$ to match the top five percent income share in the U.S., which is $30 \%$. This is a reasonable approximation given that the top earners are entrepreneurs both in the model and the U.S. data.
} 
some variation across countries in the predicted entrepreneurship rates. These gaps partly explain the dispersion in entrepreneurship across countries, with a correlation between actual and predicted shares of $10 \%$ in the case of employers and $6.7 \%$ in the self-employed workers case. To give an idea of the model goodness of fit for the OECD sample, the average absolute deviation of the model is $44 \%$ for the share of employers and $61 \%$ for the self-employed share.

When computing the numerical results in the next two subsections, we distinguish between the short run and the long run. In the short run, capital is taken as constant and, therefore, not affected by the introduction of the gender gaps $\left(\mu, \mu_{o}, \lambda\right)$; in the long run, on the other hand, the capital stock takes its steady-state value and, therefore, is negatively affected by the introduction of the gender gaps. ${ }^{26}$ To compute the steady-state capital stock, we assume a gross interest rate of 0.125 , which is consistent with a depreciation rate of 0.075 and an intertemporal discount factor of 0.05 in a continuous-time model. ${ }^{27}$ Given that the output elasticity to the capital stock is only $\alpha \eta=0.09$, the long-run results do not differ much to the short-run ones.

\subsection{Income effects from gender gaps}

Table 2 shows the effect on (market) income per worker caused by the introduction of the different gender gaps considered in this paper. As stated above, women are assumed to be identical to men in all dimensions, so in the absence of gender gaps, their occupational choices would be the same as those of males. When the gender gaps $\left(\mu, \mu_{0}, \lambda\right)$ are introduced, however, the efficient allocation is distorted and, as a result, there is a decline in aggregate income per worker and per capita.

The first row shows that if all women were excluded from employership $(\mu=0)$ but not from self-employment $\left(\mu_{0}=1\right)$ the income per capita loss would be $7.1 \%$ in the short run and 8.62 in the long run. In the second row we see that if all women were excluded from becoming entrepreneurs $\left(\mu=0\right.$ and $\left.\mu_{0}=0\right)$, i.e. both employers and self-employed, income per worker would fall by $10.1 \%$ in the short run and $11 \%$ in the long run. Naturally, the largest effect on (market) income per capita occurs when all women are excluded from the labor market $\lambda=0$, which, given our assumptions, is equivalent to reducing the labor force by $50 \%$. As we can see in the third row of the table, in this case, income per capita falls by almost $47 \%$ in the short run and $50 \%$ in the long run.

\footnotetext{
${ }^{26}$ The value for the stock of capital used in the short run is irrelevant, since the income loss predicted by the model due to the introduction of gender gaps is not affected by its value.

${ }^{27}$ The intertemporal discount factor we use is similar to the one proposed by Cooley and Prescott (1995), while the value for the depreciation rate is roughly an average of values found in the literature; for example, 0.048 in Cooley and Prescott (1995) and 0.1 in Christiano et al. (2005).
} 
Table 2: Potential income losses from gender gaps

\begin{tabular}{ccc}
\hline & Short Run & Long Run \\
\hline \hline $\begin{array}{c}\text { Due to highest possible employership-gap } \\
\left(\mu=1, \rightarrow \mu=0 ; \mu_{0}=1, \lambda=1\right)\end{array}$ & $7.1 \%$ & $8.6 \%$ \\
$\begin{array}{c}\text { Due to highest possible } \text { entrepreneurship-gap } \\
\left(\mu=1, \mu_{0}=1 \rightarrow \mu=0, \mu_{0}=0 ; \lambda=1\right)\end{array}$ & $10.1 \%$ & $11 \%$ \\
$\quad \begin{array}{l}\text { Due to highest possible } \text { lfp-gap } \\
\left(\lambda=1 \rightarrow \lambda=0 ; \mu=1, \mu_{o}=1\right)\end{array}$ & $46.8 \%$ & $50 \%$ \\
\end{tabular}

\subsection{Cross-country results: OECD sample}

In this section, we use labor market data for 33 OECD countries for the year 2010 to quantify the income effects of the observed gender gaps. ${ }^{28}$ The variables used are: labor force participation by gender, fraction of employers (or self-employed with employees) by gender and fraction of own-account workers (or self-employed without employees) by gender, which we denote as self-employed in our paper. Although, in line with the theoretical literature, one could have expected low gender gaps in the labor market in OECD countries compared to the rest of the world, these gaps are still sizable in many cases, as we will see in the next subsection.

\subsubsection{Country-specific gender gaps}

For each country in our sample, we compute the parameters associated with the gender gaps $\left(\mu, \mu_{o}, \lambda\right)$ comparing the male and female data on labor force participation, share of employers and share of self-employed. The numerical results for each OECD country are presented in Appendix B.

The parameter $\lambda$, which denotes the fraction of women not excluded from the labor force, is computed as the ratio of female labor force relative to the male labor force. The average labor force participation-gender gap, defined as $1-\lambda$ is 0.22 , i.e. out of every hundred men who participate in the labor market there are only 78 women doing so. This gap ranges from 0.61 in Turkey to 0.08 in Iceland, Finland and Norway. Similarly, the parameter $\mu$ is computed as the share of female employers - defined as female employers over female employment- over the share of male employers. The average gap in employers $(1-\mu)$ is 0.62 , varying from a value of 0.81 in Turkey to 0.38 in Australia. Finally, the parameter $\mu_{o}$ is inferred from the

\footnotetext{
${ }^{28}$ OECD (2014), "Gender Equality: Gender equality in entrepreneurship", OECD Social and Welfare Statistics (database).
} 
Table 3: Average income losses from gender gaps - OECD sample

\begin{tabular}{|c|c|c|c|c|}
\hline \multirow{2}{*}{$\%$} & \multicolumn{2}{|c|}{ Short-run income loss } & \multicolumn{2}{|c|}{ Long-run income loss } \\
\hline & Due to $\left(\mu, \mu_{o}\right)$ & Due to $\left(\mu, \mu_{o}, \lambda\right)$ & Due to $\left(\mu, \mu_{o}\right)$ & Due to $\left(\mu, \mu_{o}, \lambda\right)$ \\
\hline Top $25 \%$ & 5.06 & 19.7 & 5.72 & 21.5 \\
\hline 50 to 75 percentile & 4.88 & 13.8 & 5.47 & 15.1 \\
\hline 25 to 50 percentile & 5.20 & 12.5 & 5.80 & 13.7 \\
\hline Bottom 25\% & 5.17 & 9.61 & 5.77 & 10.6 \\
\hline
\end{tabular}

data to match the female share of self-employment relative to the male one, given the value of $\mu$. The entrepreneurship-gender gap, defined as the fraction of "women" excluded from both employership and self-employment, is calculated as $(1-\mu)\left(1-\mu_{o}\right)$ and it is equal to 0.43 on average, ranging from 0.69 in Ireland to 0 in Chile. ${ }^{29}$ The employership-gender gap, defined as the fraction of women excluded from employership but not from self-employment, is calculated as $(1-\mu) \mu_{o}$, is equal to 0.18 on average, ranging from 0.53 in Turkey to 0 in Ireland and Poland.

\subsubsection{Cross-country results}

The cross-country results for the OECD sample are summarized in Table 3, which shows the effects of introducing all the gender gaps analyzed - the $\left(\mu, \mu_{0}, \lambda\right)$ gaps - and the effects of introducing the occupational gender gaps to employership and self-employment - the $\left(\mu, \mu_{o}\right)$ gaps - both in the short run, when the capital stock is fixed, and the long run, when the capital stock takes its steady-state value. Countries are classified in four groups depending on their total income loss: countries above the $75^{\text {th }}$ percentile, countries between the $50^{\text {th }}$ and $75^{\text {th }}$ percentile, countries between the $25^{\text {th }}$ and $50^{\text {th }}$ percentile and those below the $25^{\text {th }}$ percentile. As it is apparent from the table, not surprisingly, the long run costs for each group are substantially larger than the short run ones. The table also reveals that the fraction of the total income losses represented by the restrictions on entrepreneurship represent about $40 \%$ of the total income loss, with the reminding loss being generated by the gaps in labor force participation.

The costs for each OECD country are presented in Appendix B. The average income loss due to the gender gaps in this sample of countries is $15.4 \%$ in the long run and $14.1 \%$ in the short run, while the income loss due to gender gaps in employership and self-employment are $5.7 \%$ in the long run and $5 \%$ in the short run. The countries with the largest average total losses in the long run are Turkey (33.1\%), Mexico (25.5\%), and Italy (21.2\%), while

\footnotetext{
${ }^{29} \mathrm{~A}$ zero gap in Chile reflects the fact that, according to our calculations, in this country no women is excluded from both employership and self-employment.
} 
Iceland (9.2\%), Norway (9.7\%), and Finland (9.7\%) display the smallest losses. The countries with the largest average losses generated by distortions in entrepreneurship in the long run are Israel (7.4\%), Turkey (7.3\%), and Estonia (7.2\%). Chile (2.7\%), Australia (3.5\%), and Poland (4.7\%) display the smallest losses associated with distortions in entrepreneurship.

\section{Extension: out-of-necessity self-employment}

\subsection{Model with out-of-necessity self-employment}

In this section, we present and simulate an extended version the model to make it more suitable for developing countries, which display a much larger fraction of self-employed workers than developed countries. ${ }^{30}$ One possible explanation for this difference is the existence of the socalled out-of-necessity entrepreneurs, who choose this occupation because they had no other occupational choices apart from taking advantage of a business opportunity. ${ }^{31}$ To capture this phenomenon, in the extended model, a fraction $1-\theta$ of both males and females are not allowed to become workers and, as we can see in Figure (6) in Appendix A, they choose to become self-employed.

The agents' optimization problem and occupation map in this version of the model is exactly the same as the one discussed in Section 3. However, the market-clearing conditions are now different to reflect the new restrictions in the labor market. The capital market clearing can be written as

$$
\begin{aligned}
k & =\frac{1}{2}\left[\int_{z_{2}}^{\infty} k(x) d \Gamma(x)+\int_{z_{1}}^{z_{2}} \tilde{k}(x) d \Gamma(x)+(1-\theta) \int_{B}^{z_{1}} \tilde{k}(x) d \Gamma(x)\right] \\
& +\frac{\lambda}{2}\left[\mu \int_{z_{2}}^{\infty} k(x) d \Gamma(x)+\left(\mu+(1-\mu) \mu_{0}\right) \int_{z_{1}}^{z_{2}} \tilde{k}(x) d \Gamma(x)\right] \\
& +\frac{\lambda}{2}\left[(1-\mu) \mu_{0} \int_{z_{2}}^{\infty} \tilde{k}(x) d \Gamma(x)+(1-\theta)\left(\mu+(1-\mu) \mu_{0}\right) \int_{B}^{z_{1}} \tilde{k}(x) d \Gamma(x)\right]
\end{aligned}
$$

where the upper term is the demand for capital by men and the lower term is the women's demand for capital . Compared to equation (8), the demand for capital has now two new components: the last terms in the first and second lines, which correspond to the capital demand of male and female out-of-necessity self-employed. A fraction $(1-\theta)$ of males with

\footnotetext{
${ }^{30}$ According to the data, the overall fraction of self-employed (own-account workers in the ILO dataset) is less than $11 \%$ in OECD countries and almost $35 \%$ in developing countries.

${ }^{31}$ Using data from the Global Entrepreneurship Monitor survey, Poschke (2013) fins that necessity entrepreneurs represent almost $50 \%$ of all entrepreneurs in non-OECD countries.
} 
ability below $z_{1}$ become self-employed since they would like to be workers but are not allowed to do so and choose their second-best option. Moreover, a fraction $(1-\theta)$ of females with ability below $z_{1}$ would like to be workers but, since they are "excluded" from this occupation, they choose to become out-of-necessity self-employed if they are eligible to do so, i.e. if they are not excluded from entrepreneurship ${ }^{32}$ These out-of-necessity self-employed demand the optimal amount of capital given their talent or ability. Similarly, the labor market-clearing condition is given by

$$
\begin{array}{r}
\frac{1}{2}\left[\int_{z_{2}}^{\infty} n(x) d \Gamma(x)\right]+\frac{\lambda}{2} \mu\left[\int_{z_{2}}^{\infty} n(x) d \Gamma(x)\right]= \\
\frac{1}{2} \theta \Gamma\left(z_{1}\right)+\frac{\lambda}{2} \theta\left[\Gamma\left(z_{1}\right)+(1-\mu)\left(1-\mu_{0}\right)\left(1-\Gamma\left(z_{1}\right)\right)\right],
\end{array}
$$

where the first line represents the aggregate labor demand and the second line represents the aggregate labor supply. Compared to equation (9), the only difference here is that the labor supply terms are multiplied by the parameter $\theta$, given that a fraction $(1-\theta)$ of both males and females are not allowed to become workers.

\subsection{Extended model numerical results}

To simulate the extended model, we use the talent distribution function described in equation (11) and the parameter values of Table 1 used in the simulations of the benchmark model. Table 4 shows the effects of the occupational gaps on income per capita when the parameter $\theta$ is smaller than 1, i.e. when at least a fraction of agents who want to be workers are not allowed to do so. Interestingly, the effect of the employership gap decreases with the $\theta$-friction, since a fall in $\theta$ reduces the general equilibrium effect of the $\mu$-gap on the wage rate and, hence, reduces the negative effect on the aggregate productivity of entrepreneurs. ${ }^{33}$ The effect of the of the entrepreneurship gap, however, increases with $\theta$, given that excluding females from employership and self-employment implies excluding from the labor force a fraction $(1-\theta)(1-\mu)\left(1-\mu_{o}\right)$, as we can see in Figure (6) in Appendix A.

\footnotetext{
${ }^{32}$ Note that since the entrepreneurship friction is $(1-\mu)\left(1-\mu_{o}\right)$, a fraction $1-(1-\mu)\left(1-\mu_{o}\right)=\mu+$ $(1-\mu) \mu_{o}$ are not excluded from self-employment.

${ }^{33}$ Intuitively, a fall in $\theta$ reduces the supply of workers and, as a result, the introduction of the $\mu$-gap creates a smaller fall in the equilibrium wage. This limits the incorporation of less talented employers and, hence, limits the fall in aggregate productivity.
} 
Table 4: Potential income losses from gender gaps

\begin{tabular}{ccccc}
\hline & \multicolumn{2}{c}{ Short Run } & \multicolumn{2}{c}{ Long Run } \\
& $\theta=.75$ & $\theta=.25$ & $\theta=.75$ & $\theta=.25$ \\
\hline \hline Due to highest possible employership-gap & $6.1 \%$ & $3 \%$ & $7.4 \%$ & 3.7 \\
$\left(\mu=1, \rightarrow \mu=0 ; \mu_{0}=1, \lambda=1\right)$ & & & & \\
$\begin{array}{c}\text { Due to highest possible entrepreneurship-gap } \\
\left(\mu=1, \mu_{0}=1 \rightarrow \mu=0, \mu_{0}=0 ; \lambda=1\right)\end{array}$ & $17 \%$ & $33.5 \%$ & $18.6 \%$ & 36.1 \\
\hline
\end{tabular}

\subsection{Cross-country results: non-OECD sample}

In this section, we use labor market data for 106 non-OECD countries from the International Labor Organization (KILM, 8th Edition) for the latest available year. As in section 4.4 , the variables used are the country's labor force participation, fraction of employers (or self-employed with employees) and fraction of own-account workers (self-employed without employees) by gender, which we denote as self-employed in our paper. ${ }^{34}$ As before, for each country, we then compute the gender gap parameters $\left(\mu, \mu_{o}, \lambda\right)$ comparing the male and female data on labor force participation, share of employers and share of self-employed. The parameter $\theta$ is jointly estimated with the other parameters to match the fraction of self-employed in each country. The numerical results for non-OECD countries are presented in Appendix C.

The average cross-country results obtained are summarized in Table (5), where the countries are split in 7 geographic regions, Central Asia (6), East Asia and the Pacific (13), Europe (13), Latin America and the Caribbean (26), Middle East and North Africa (13), South Asia (7), and Sub-Saharan Africa (28). ${ }^{35}$ For each region, columns (2) and (4) show the average income loss (in the short and long run, respectively) due to the occupational gender gaps. $\left(\mu, \mu_{o}\right)$, while columns (3) and (5) show the average income loss due to all the gender gaps $\left(\mu, \mu_{o}, \lambda\right)$. Our results suggest the existence of remarkable differences across regions in income losses due to gender gaps, especially in those generated by the female labor participation gap. The region with the largest income loss is the Middle East and North Africa where, according to our estimates, the total income loss is $35 \%$ in the short run and $38 \%$ in the long run, a fifth

\footnotetext{
${ }^{34}$ In KILM, the category "self-employed" is subdivided in four groups: employers, own-account workers, members of producers' cooperatives, and contributing family workers. Given the definition of each of these groups, we have decided that the most sensible choice was to use own-account workers to represent the selfemployed in our model, and assume that members of producers' cooperatives, and contributing family workers are workers.

${ }^{35}$ We follow the World Bank to assign each country to a region, with the exception of countries that belong in the Europe and Central Asia group, which we split in two geographical regions, Europe and Central Asia, since we believe the labor markets in these two regions are very different. The numbers in parentheses indicate the number of countries assigned to each region.
} 
Table 5: Average income losses from labor market gender gaps- non-OECD sample (by World Bank region)

\begin{tabular}{c|cc|cc}
$\%$ & \multicolumn{2}{|c|}{$\begin{array}{c}\text { Short-run income loss } \\
\text { Doe to }\left(\mu, \mu_{o}\right)\end{array}$} & $\begin{array}{c}\text { Lue to }\left(\mu, \mu_{o}, \lambda\right) \\
\text { Due to }\left(\mu, \mu_{o}\right)\end{array}$ & Due to $\left(\mu, \mu_{o}, \lambda\right)$ \\
\hline \hline Central Asia & 6.22 & 9.04 & 7.06 & 10.12 \\
East Asia and Pacific & 7.09 & 14.60 & 7.84 & 15.95 \\
Europe & 4.86 & 9.83 & 5.43 & 10.82 \\
Latin America \& C. & 4.67 & 15.76 & 5.29 & 17.28 \\
Middle East \& N. Africa & 6.90 & 35.11 & 7.72 & 37.83 \\
South Asia & 8.79 & 22.94 & 9.75 & 24.91 \\
Sub-Saharan Africa & 5.29 & 10.82 & 5.96 & 11.95 \\
\hline
\end{tabular}

of which is due to the occupational choice gaps. South Asia has the second largest income losses due to gender gaps, $23 \%$ in the short run and $25 \%$ in the long run, almost $40 \%$ of which is due to occupational gaps. Central Asia, on the other hand, is the region with the lowest total income loss due to gender gaps, $9 \%$ in the short run and 10.1 in the long run, almost $70 \%$ of which is due to occupational gaps.

Appendix $\mathrm{C}$ contains the results for all countries in the non-OECD sample, together with the country-specific parameter estimates. The average $\theta$ is 0.75 , indicating that only $25 \%$ of agents who want to be workers end up being self-employed instead. The average $\mu$ is 0.44 , the average $\mu_{o}$ is 0.54 and the average $\lambda$ is 0.74 . The average income loss from all gender gaps is $16.05 \%$ in the short run and $17.53 \%$ in the long run, while the average income loss due to occupational gaps is $5.8 \%$ in the short run and $6.5 \%$ in the long run. These figures are higher than for the sample of OECD countries, although the fact that we use different versions of the models to calculate the costs in each group suggests that this comparison should be taken cautiously. With respect to the long-run total income losses from gender gaps, Yemen, Saudi Arabia, Syria, Qatar and Iran are the countries with the largest ones, all of them over 40\%, while Ghana, Liberia and Rwanda are the countries with the smallest figures, all of them around $1 \%$. With respect to the long-run income losses due to occupational gender gaps, Bangladesh, Burkina Faso and Pakistan are the countries with the largest ones, all of them above $17 \%$, while Lesotho, Nepal, Rwanda and Bhutan are the countries with the smallest ones, in all cases below $1 \%$.

After merging the OECD and the non-OECD, we summarize the results in Figures (3) and (4). Figure (3) shows the long-run total income loss due to gender gaps of each country in a world map, where we can see the largest losses are in Middle East and Northern Africa, South Asia and Latin America. Figure (4), on the other hand, plots the income losses against GDP per capita in 2010. The first plot shows that there is an inverse- $U$ relationship between the level of development of a country and the total income loss caused by the gender gaps, while 
Figure 3: World map of total income losses due to gender gaps

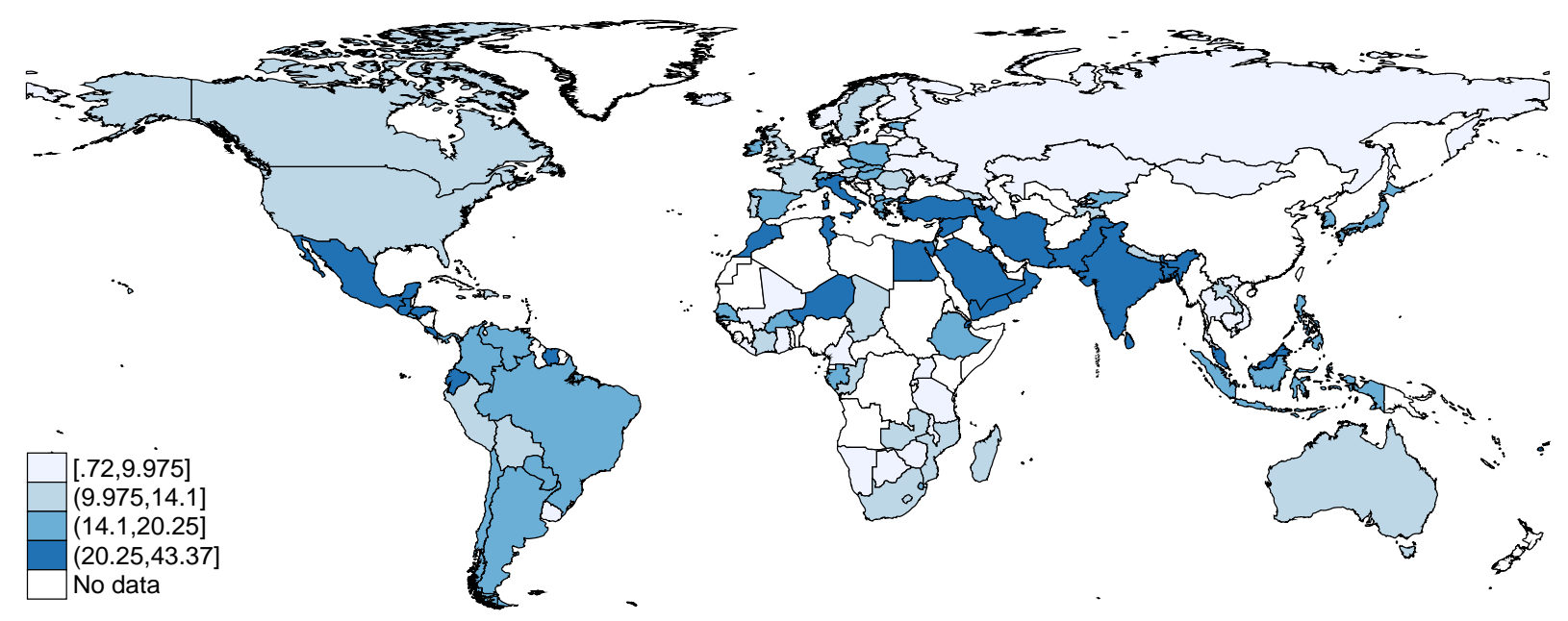

the second plot shows a negative relationship between the development level and the income losses caused by the gender gaps in entrepreneurship. This suggests that the inverse- $U$ in the first plot is mostly driven by the U-shaped relationship between development and female labor force participation discussed, for example, in Goldin (1995). ${ }^{36}$

\section{Conclusion}

This paper presents an occupational choice model and uses it to quantify the effects of gender gaps in the labor market on aggregate productivity and income per capita. Our numerical results show that gender gaps in entrepreneurship have significant effects on the allocation of resources and thus on aggregate productivity, while the gap from labor force participation has a large effect on income per capita. Specifically, if no women worked as an employer or a self-employed, our benchmark model predicts that income per worker would drop by around $10 \%$ in the short run and $11 \%$ in the long run, while if the labor force participation of women was zero, income per capita would decrease by almost $47 \%$ in the short run and $50 \%$ in the long run. When we carry out the country-by-country analysis, we find that there are important differences across countries and geographical regions. Gender inequality creates an average income loss of $14 \%$ in the short run and $15.4 \%$ in the long run for the OECD

\footnotetext{
${ }^{36}$ Countries at different stages of their development process differ in many aspects, including the optimal choices of women in the labor market. In this sense, the interpretation of our gender gaps may not be the same across countries in different income groups and, as a result, the comparison between OECD and non-OECD should be taken with caution. An alternative to comparing gender gaps in a cross-section of countries at different stages of development, would be to use time series or panel data to compare these gaps - and their costs for one or several countries over time. An endogenous growth model where we introduce gender gaps in the labor market would be the appropriate conceptual tool in that case since it would allow use to analyze the two-directional link between gender inequality and economic growth. We leave this for future research.
} 
Figure 4: Income losses and development level
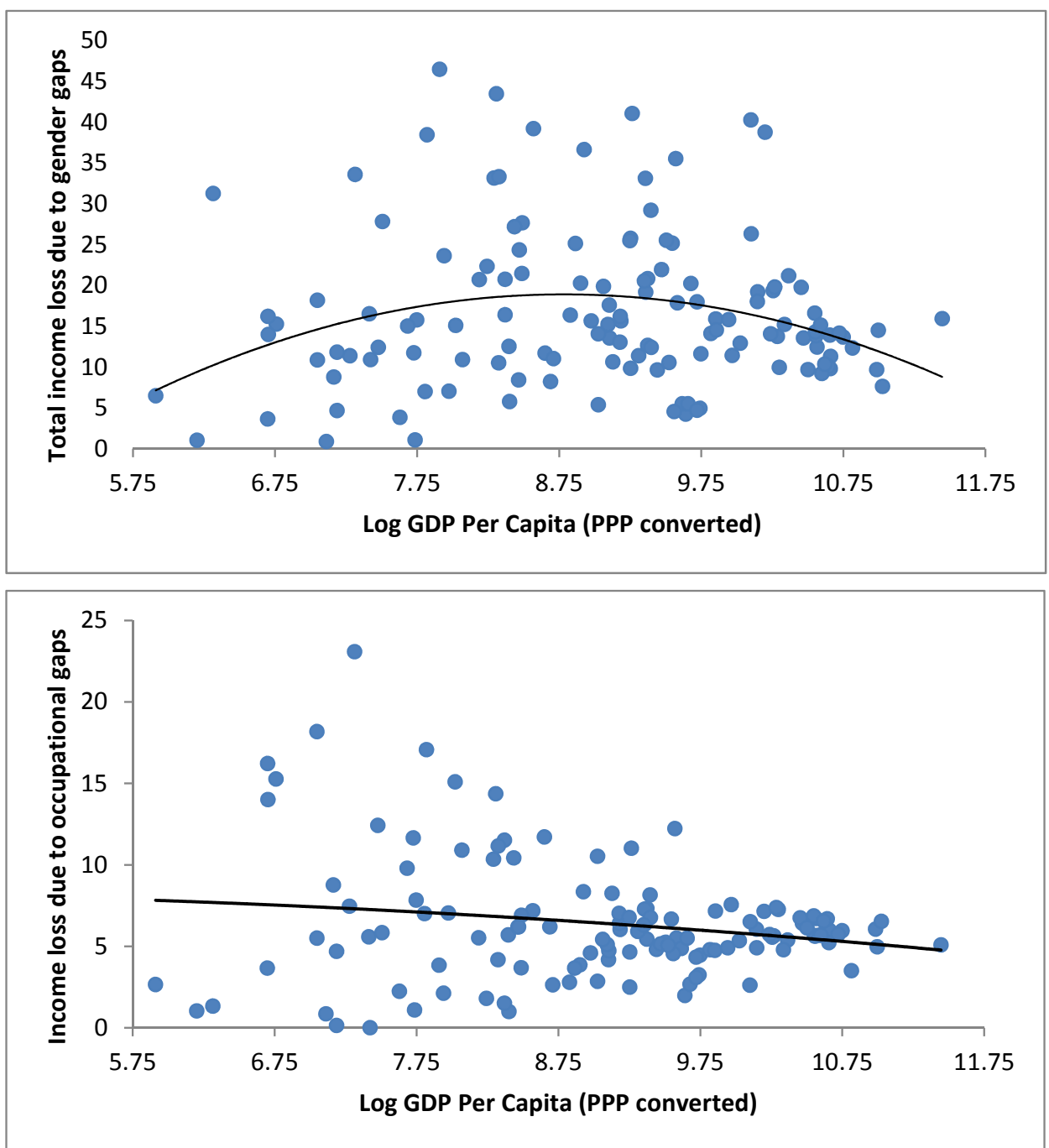
sample, and an average income loss of of $16 \%$ in the short run and $17.5 \%$ in the long run for the sample of developing countries. On average, $44 \%$ of those losses are due to gender gaps in occupational choices. The region with the largest income loss due to gender inequality is Middle East and North Africa, with an average income loss of $38 \%$ in the long run, followed by South Asia and Latin America and the Caribbean, with long-run income losses of $25 \%$ and $17.3 \%$, respectively.

Our results suggest that the costs associated with gender gaps in the labor markets are substantial. As explained in OECD (2014), there are several public policies that can increase gender equality in the labor market: fostering a gender neutral legal framework for business, reducing administrative burdens on firms and excessive regulatory restrictions, ensuring equal access to finance for female and male entrepreneurs, and pair relevant financing schemes with support measures such as financial literacy, training, mentoring, coaching and consultancy services, and increasing access to support networks, including professional advice on legal and fiscal matters. A recent example of a country that has implemented some of these policies is Norway, where in 2006, its government established a quota system that made it mandatory for companies to have at least $40 \%$ of women in their boards (Bertrand et al., 2014). Other countries have now implemented regulations that force companies listed in the stock exchange to comply with Corporate Governance Codes (CDC's). In view of our findings, public policies along these lines may increase efficiency in the labor market and result in substantial gains in productivity and, potentially, women's welfare.

As discussed before, in this paper, we abstract from modeling the decision of agents to participate in the labor force, as well as any differential aspect in the occupational choices of women. An interesting extension would be to introduce a household production sector in the model, which is likely to lead to a division of labor between husbands and wives, as in Becker (1981). This would obviously reduce the welfare effects of the labor force participation gender gap, although it would also reduce the female value of participating in the labor market and, hence, the optimal female labor supply. Similarly, we also abstract from sectoral differences in terms of female labor intensity, which seem to exist in the real world. Taking into account the imperfect substitution of male and female labor, together with the differences in female labor intensity by sector, would probably raise the losses predicted by the model. On the other hand, if one assumed that women have less entrepreneurial talent than men - perhaps due to gender gaps in education - then our framework is likely to overestimate the negative impact of gender gaps in entrepreneurship on aggregate income. 


\section{Acknowledgments}

We thank the editor, Joe Kaboski, and the editor-in-chief, Isaac Ehrlich, for their excellent guidance to improve our paper. We also thank seminar participants at Universitat Autonoma de Barcelona, University of Sheffield, University of Birmingham, Bank of Italy, Clemson University, Universitat de Barcelona, University of Cagliari, The World Bank, Washington State University, Liverpool Management School, John Carroll University, Clark University, as well as conference participants at the "Labor Markets in the Aftermath of the Global Financial Crisis" (IMF), and "Structural Change, Dynamics, and Economic Growth", and the helpful comments of Raquel Fernandez, Xavier Gine, Ian Gregory-Smith, Stephen Machin, Luigi Pistaferri, Xavier Raurich, Fernando Sanchez-Losada, Curtis Simon, Robert Tamura and Montserrat Vilalta-Bufí, as well as several referees. Teignier acknowledges financial support from Spanish Ministry of Economy and Competitiveness, Grant ECO2012-36719, and from Generalitat of Catalonia, Grant SGR2014-493. All remaining errors are ours.

\section{References}

Abu-Ghaida, D, and S. Klasen, 2004. "The Costs of Missing the Millennium Development Goal on Gender Equity," World Development 32(7), 1075-107.

Amaral, P., and E. Quintin, 2010. "Limited Enforcement, Financial Intermediation and Economic Development: A Quantitative Assessment," International Economic Review, 51(3), 785-811.

Antunes, A., T. Cavalcanti, and A. Villamil, 2008. "The Effect of Financial Repression and Enforcement on Entrepreneurship and Economic Development." Journal of Monetary Economics, 55(2), 278-298.

Barsh, J., and L. Yee, 2012. "Unlocking the Full Potential of Women at Work." McKinsey \& Company/Wall Street Journal.

Barro, R. J., and J. W. Lee, 1993. "International Comparisons of Educational Attainment." Journal of Monetary Economics 32(3): 363-394.

Barro, R. J., and X. Sala-i-Martin, 2003. Economic Growth. Second Edition. The MIT Press: Cambridge.

Becker, G. S., 1981. "A Treatise on the Family." Harvard University Press, Cambridge, MA.

Becker, G S., Hubbard, H. J., and Murphy, K. M. 2010. "The Market for College Graduates and the Worldwide Boom in Higher Education of Women." American Economic Review, 
100(2): 229-33.

Becker, G.S., and H.G. Lewis. 1973. "On the Interaction between the Quantity and Quality of Children." Journal of Political Economy, 81: S279-S88.

Becker, G. S., W. H. J. Hubbard, and K. M. Murphy, 2010. "Explaining the Worldwide Boom in Higher Education of Women." Journal of Human Capital, 4(3), Fall, 203-241.

Bertrand, M, S. E. Black, S. Jensen, and A. Lleras-Muney, 2014.'Breaking the Glass Ceiling? The Effect of Board Quotas on Female Labor Market Outcomes in Norway." NBER working paper 20256.

Bhattacharya, D., Guner, N., and Ventura, G., 2013. "Distortions, Endogenous Managerial Skills and Productivity Differences." Review of Economic Dynamics, 16(1), 11-25.

Blau, F.D., and L.M. Kahn., 2007. The Gender Pay Gap: Have Women Gone as Far as They Can? Academy of Management Perspectives 21(1): 7.

Blau, F.D., and L.M. Kahn., 2013. Female Labor Supply: Why Is the US Falling Behind? NBER Working Paper 18702.

Brush, C.G., P.G. Greene, D.J. Kelley and Y. Litovsky (2011), 2010 Women's Report, Global Entrepreneurship Monitor Executive Report, Babson College, United States.

Buera, F. J., and Y. Shin., 2011. Self-Insurance vs. Self-Financing: A Welfare Analysis of the Persistence of Shocks." Journal of Economic Theory 146, 845-862.

Buera, F.J., and Y. Shin, 2013. Financial Frictions and the Persistence of History: A Quantitative Exploration.” Journal of Political Economy 121(2), 221-272.

Buera, F. J., Kaboski, J. P., and Shin, Y., 2011. "Finance and Development: A Tale of Two Sectors." American Economic Review 101(5), 1964-2002.

Cavalcanti, T., and Tavares, J., 2011. "The Output Cost of Gender Discrimination: A Model-Based Macroeconomic Estimate." Forthcoming, Economic Journal..

Christiano, L. J., Eichenbaum, M., and C. L. Evans, 2005. "Nominal Rigidities and the Dynamic Effects of a Shock to Monetary Policy." Journal of Political Economy 113(1): 1-45.

Cole, R.A. and H. Mehran,2009. "Gender and the Availability of Credit to Privately Held Firms:Evidence from the Surveys of Small Business Finances", Federal Reserve Bank of New York Staff Report, No. 383, August.

Coleman, S. and A.M. Robb, 2012. A Rising Tide, Financing Strategies for Women-owned Firms, Stanford University Press, Stanford, United States.

Cranfield University, 2014. "The Female FTSE 100 Report 2014 - Crossing the Finish Line", Cranfield University, School of Management (www.som.cranfield.ac.uk/som/dinamiccontent/research/ftse/The\%20Female\%20FTSE\%20Board\%20Report\%202014.pdf

Cooley, T. F., and E. C. Prescott (1995) "Economic Growth and Business Cycles" in Frontiers of Business Cycle Research, ed. Thomas F. Cooley, 1995, Princeton University 
Press, 1-38.

Cuberes, D., and Teignier, M., 2014. "Gender Inequality and Economic Growth: A Critical Review." Journal of International Development, 26(2): 260-276.

Doepke, M., and M. Tertilt. 2009. Women's Liberation: What's in it for Men? Quarterly Journal of Economics 124(4): 1541-91.

Dollar D., and Gatti, R., 1999. "Gender Inequality, Income and Growth: Are Good Times Good for Women?" Policy Research Report on Gender and Development Working Paper Series No. 1. World Bank, Washington, DC.

Elborgh-Woytek, M. Newiak, K. Kochhar, S. Fabrizio, K. Kpodar, P. Wingender, B. Clements, and G. Schwartz, 2013. "Women, Work, and the Economy: Macroeconomic Gains from Gender Equity." IMF Discussion Note, September 2013.

Erosa, A., T. Koreshkova, and D. Restuccia, 2010.: "How Important is Human Capital? A Quantitative Theory Assessment of World Income Inequality." Review of Economic Studies , $77(4), 1421-1449$.

Esteve-Volart, B., 2009. "Gender Discrimination and Growth: Theory and Evidence from India." Manuscript.

Eurobarometer, 2013. http://ec.europa.eu/public_opinion/index_en.htm

Eurostat,2008., "Statistics Explained: Factors of Business Success Survey", Luxembourg.

Fernandez, R., 2009. "Women's Rights and Development." NBER Working Paper No 15355.

Galor, O., and Weil, D. N., 1996. "The Gender Gap, Fertility, and Growth." American Economic Review 85(3), 374-387.

Goldin, C., 1990. "Understanding the Gender Gap: An Economic History of American Women." Cambridge University Press, Cambridge.

Goldin, C., 1995. "The U-Shaped Female Labor Force Function in Economic Development and Economic History." In: Schultz, Investment in Women's Human Capital and Economic Development, University of Chicago Press, 61-90.

Gollin, D., 2008. "Nobody's Business but My Own: Self Employment and Small Enterprise in Economic Development. Journal of Monetary Economics." 55(2), 219-233.

Greenwood, J., A. Seshadri, and M. Yorukoglu, 2005. "Engines of Liberation. Review of Economic Studies." 72: 109-33.

Hsieh, C., Hurst, E., Jones, C., and Klenow, P., 2013. "The Allocation of Talent and U.S. Economic Growth." NBER Working Paper No. 18693.

International Labor Organization, Table 3 http://kilm.ilo.org/KILMnetBeta/default2.asp

Klasen, S., 2002. "Low Schooling for Girls, Slower Growth for All? Cross-Country Evidence on the Effect of Gender Inequality in Education on Economic Development." World Bank Economic Review 16(3), 345-373. 
Klasen, S., and Lamanna, F., 2009. "The Impact of Gender Inequality in Education and Employment on Economic Growth: New Evidence for a Panel of Countries." Feminist Economics 15 (3), 91-132.

Lagerlöf, N-P., 2003. "Gender Equality and Long Run Growth." Journal of Economic Growth 8, 403-426.

Lagerlöf, N-P., 2006. "The Galor-Weil Model Revisited: A Quantitative Exercise." Review of Economic Dynamics 9(1), 116-142.

Lucas Jr., R. E., 1978. "On the Size Distribution of Business Firms." The Bell Journal of Economics 9(2), 508-523.

Macchiavello, R., Menzel, A., and Woodruff, C., 2014. "Managerial Capital and Productivity: Evidence from a Training Program in the Bangladeshi Garment Sector." Working Paper.

Morrisson, C., and Murtin, F., 2009. "The Century of Education." Journal of Human Capital 3(1), 1-42.

Ngai, R., and Petrongolo, B., 2013. "Gender Gaps and the Rise of the Service Economy." CEP DP1204.

Olivetti, C., and Petrongolo, B., 2008. "Unequal Pay or Unequal Employment? A Crosscountry Analysis of Gender Gaps.” Journal of Labor Economics 26(4), October, 621-654.

Olivetti, C., and Petrongolo, B., 2014. "Gender Gaps across Countries and Skills: Demand, Supply and the Industry Structure." Review of Economic Dynamics 17(4), October, 842-859.

OECD 2012. Closing the Gender Gap, Act Now, OECD Publishing, Paris.

OECD 2013., OECD Education at a Glance - Education Indicators, OECD Publishing, Paris,

OECD 2014., Enhancing Women's Economic Empowerment through Entrepreneurship and Business Leadership in OECD Countries, Background Report to China Development research Foundation project on Enhancing Women's Economic Empowerment through Entrepreneurship and Leadership in the Midst of China's New Urbanization.

Parro, F., 2012. "International Evidence on the Gender Gap in Education over the Past Six Decades: A Puzzle and an Answer to It." Journal of Human Capital, 6(2), Summer, 150-185.

Penn World Tables, 8.0. https://pwt.sas.upenn.edu/

Poschke, M., 2013. "'Entrepreneurs out of necessity": a snapshot." Applied Economics Letters 20(7), 658-663.

Thévenon, O., Nabil A., Adema, W., and del Pero A. S., 2012, "Effects of Reducing Gender Gaps in Education and Labour Force Participation on Economic Growth in the OECD," OECD Social, Employment and Migration Working Papers, No. 138, OECD Publishing, Paris. 
Tzannatos, Z., 1999. "Women and Labor Market Changes in the Global Economy: Growth Helps, Inequalities Hurt and Public Policy Matters." World Development 27 (3), 551-569. World Bank, 2001. Engendering Development. Washington, DC: World Bank. 


\section{A Occupational choice maps of women}

The two figures below illustrate how women's constraints are linked to their talent draw and what they imply in terms of their occupational choice. The first figure shows the occupational choice map of women in the benchmark model, while the second figure shows the one in the extended model with necessity entrepreneurs.

Figure 5: Occupational choice map of women - benchmark model

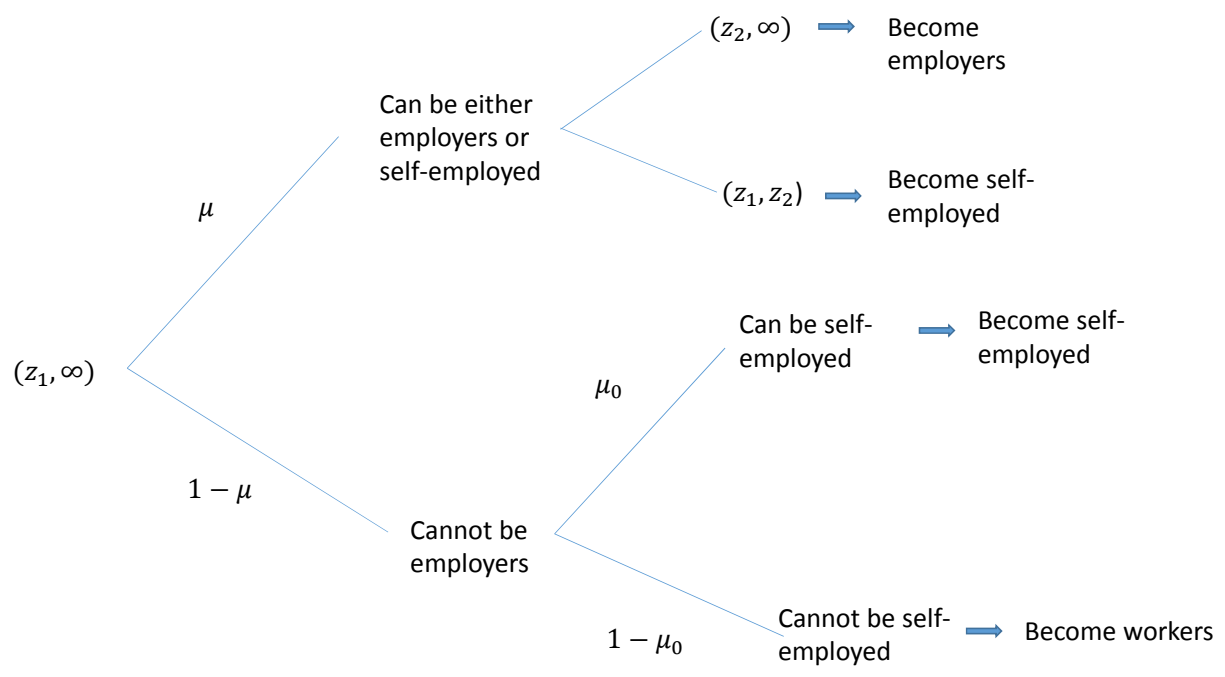

Figure 6: Occupational choice map of women - extended model

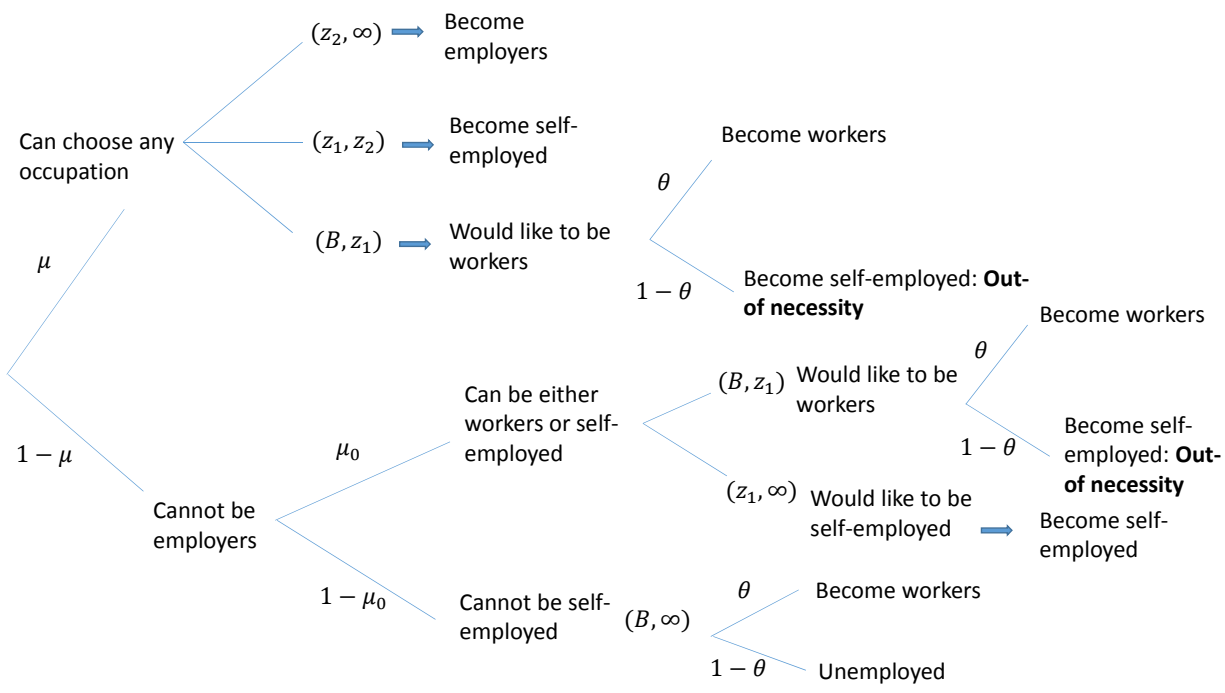




\section{B Cross-country results: OECD sample ${ }^{37}$}

\begin{tabular}{c|ccc|cc|cc}
\hline (Year 2010) & $\mu$ & $\mu_{o}$ & $\lambda$ & 1 & 2 & 3 & 4 \\
\hline \hline Australia & 0.62 & 0.02 & 0.81 & 3.18 & 11.27 & 3.50 & 12.32 \\
Austria & 0.40 & 0.50 & 0.80 & 4.57 & 12.61 & 5.22 & 13.92 \\
Belgium & 0.39 & 0.24 & 0.78 & 5.08 & 13.81 & 5.67 & 15.14 \\
Canada & 0.38 & 0.35 & 0.87 & 4.98 & 10.23 & 5.61 & 11.31 \\
Chile & 0.64 & 1.00 & 0.63 & 2.25 & 18.48 & 2.68 & 20.24 \\
Czech Republic & 0.36 & 0.22 & 0.73 & 5.44 & 16.48 & 6.06 & 18.02 \\
Denmark & 0.30 & 0.21 & 0.87 & 6.02 & 11.31 & 6.70 & 12.45 \\
Estonia & 0.24 & 0.39 & 0.83 & 6.34 & 13.15 & 7.16 & 14.53 \\
Finland & 0.35 & 0.25 & 0.92 & 5.49 & 8.77 & 6.14 & 9.70 \\
France & 0.32 & 0.25 & 0.83 & 5.74 & 12.32 & 6.41 & 13.55 \\
Germany & 0.38 & 0.34 & 0.80 & 5.03 & 12.99 & 5.66 & 14.29 \\
Greece & 0.39 & 0.36 & 0.69 & 4.93 & 17.69 & 5.55 & 19.36 \\
Hungary & 0.48 & 0.20 & 0.79 & 4.31 & 12.89 & 4.79 & 14.12 \\
Iceland & 0.39 & 0.20 & 0.92 & 5.10 & 8.35 & 5.68 & 9.21 \\
Ireland & 0.31 & 0.00 & 0.77 & 6.27 & 15.24 & 6.86 & 16.61 \\
Israel & 0.23 & 0.32 & 0.85 & 6.56 & 12.48 & 7.37 & 13.77 \\
Italy & 0.41 & 0.26 & 0.64 & 4.81 & 19.43 & 5.38 & 21.20 \\
Japan & 0.29 & 0.23 & 0.70 & 6.06 & 18.09 & 6.75 & 19.76 \\
Korea & 0.39 & 0.27 & 0.68 & 5.04 & 18.13 & 5.64 & 19.81 \\
Luxembourg & 0.41 & 0.57 & 0.76 & 4.42 & 14.45 & 5.07 & 15.93 \\
Mexico & 0.38 & 0.70 & 0.54 & 4.51 & 23.39 & 5.25 & 25.53 \\
Switzerland & 0.40 & 0.12 & 0.81 & 5.19 & 12.91 & 5.74 & 14.13
\end{tabular}

\footnotetext{
${ }^{37}$ Variable 1: Short-run income loss due to occupational gender gaps (\%); variable 2: short-run total income loss due to gender gaps (\%); variable 3: long-run income loss due to occupational gender gaps (\%); variable 4: long-run total income loss due to gender gaps (\%).
} 


\begin{tabular}{c|ccc|cc|cc}
\hline (Year 2010) & $\mu$ & $\mu_{o}$ & $\lambda$ & 1 & 2 & 3 & 4 \\
\hline \hline Turkey & 0.19 & 0.65 & 0.39 & 6.28 & 30.53 & 7.29 & 33.11 \\
United Kingdom & 0.40 & 0.17 & 0.81 & 5.05 & 12.61 & 5.61 & 13.83 \\
United States & 0.38 & 0.14 & 0.82 & 5.37 & 12.47 & 5.95 & 13.66
\end{tabular}

\section{Cross-country results: non-OECD sample ${ }^{38}$}

\begin{tabular}{|c|c|c|c|c|c|c|c|c|c|c|}
\hline Country & Year & Region & $\theta$ & $\mu$ & $\mu_{o}$ & $\lambda$ & 1 & 2 & 3 & 4 \\
\hline ATG & 2001 & $\mathrm{LAC}$ & 1.00 & 0.51 & 0.34 & 0.99 & 3.86 & 4.18 & 4.34 & 4.69 \\
\hline $\mathrm{ARG}$ & 2011 & $\mathrm{LAC}$ & 0.92 & 0.46 & 0.40 & 0.72 & 4.89 & 16.30 & 5.49 & 17.85 \\
\hline ARM & 2011 & $\mathrm{CA}$ & 0.79 & 0.31 & 0.78 & 0.95 & 5.35 & 7.24 & 6.20 & 8.24 \\
\hline AZE & 2008 & $\mathrm{CA}$ & 0.57 & 0.19 & 1.00 & 0.98 & 3.99 & 4.81 & 4.82 & 5.71 \\
\hline BHR & 2010 & MENA & 1.00 & 0.29 & 0.00 & 0.26 & 6.51 & 36.00 & 7.14 & 38.76 \\
\hline BGD & 2005 & $\mathrm{SA}$ & 0.25 & 0.36 & 0.00 & 0.61 & 21.25 & 31.10 & 23.09 & 33.60 \\
\hline BRB & 2004 & $\mathrm{LAC}$ & 1.00 & 0.25 & 0.27 & 0.94 & 6.49 & 8.99 & 7.26 & 9.98 \\
\hline BLR & 2009 & $\mathrm{EU}$ & 1.00 & 0.46 & 0.27 & 0.99 & 4.35 & 4.91 & 4.87 & 5.48 \\
\hline BLZ & 2005 & $\mathrm{LAC}$ & 0.90 & 0.53 & 0.48 & 0.53 & 4.11 & 23.69 & 4.64 & 25.77 \\
\hline BTN & 2011 & $\mathrm{SA}$ & 0.69 & 0.83 & 1.00 & 0.90 & 0.82 & 5.20 & 0.98 & 5.76 \\
\hline BOL & 2009 & LAC & 0.72 & 0.41 & 0.74 & 0.85 & 4.98 & 11.28 & 5.70 & 12.53 \\
\hline BWA & 2010 & SSA & 1.00 & 0.66 & 1.00 & 0.85 & 2.09 & 8.83 & 2.49 & 9.83 \\
\hline BRA & 2009 & $\mathrm{LAC}$ & 0.87 & 0.48 & 0.30 & 0.78 & 5.42 & 14.30 & 6.04 & 15.67 \\
\hline BRN & 1991 & EAP & 1.00 & 0.38 & 0.34 & 0.48 & 5.02 & 26.50 & 5.65 & 28.76 \\
\hline BGR & 2011 & $\mathrm{EU}$ & 1.00 & 0.47 & 0.23 & 0.89 & 4.31 & 8.75 & 4.80 & 9.64 \\
\hline BFA & 2006 & SSA & 0.41 & 0.32 & 0.10 & 1.00 & 16.66 & 16.66 & 18.17 & 18.17 \\
\hline KHM & 2008 & EAP & 0.48 & 0.73 & 0.00 & 1.00 & 6.40 & 6.40 & 7.01 & 7.01 \\
\hline CMR & 2001 & SSA & 0.47 & 0.53 & 1.00 & 0.97 & 1.88 & 3.33 & 2.24 & 3.83 \\
\hline $\mathrm{CPV}$ & 2000 & SSA & 0.79 & 0.50 & 0.83 & 0.86 & 3.58 & 9.45 & 4.16 & 10.53 \\
\hline TCD & 1993 & SSA & 0.23 & 0.33 & 0.54 & 1.00 & 11.27 & 11.27 & 12.42 & 12.42 \\
\hline $\mathrm{COL}$ & 2011 & LAC & 0.59 & 0.48 & 0.86 & 0.71 & 3.61 & 16.00 & 4.17 & 17.58 \\
\hline
\end{tabular}

\footnotetext{
${ }^{38} 1$ st column: country codes from Penn World Tables; 2nd column: latest year for which ILO data is available; 3rd column: World Bank region (EAP: East Asia and Pacific, EU: Europe, CA: Central Asia, LAC: Latin America and the Caribbean, MENA: Middle East and North Africa, SA: South Asia, SSA: Sub-Saharan Africa). Variable 1: Short-run income loss due to occupational gender gaps (\%); variable 2: short-run total income loss due to gender gaps (\%); variable 3: long-run income loss due to occupational gender gaps (\%); variable 4: long-run total income loss due to gender gaps (\%).
} 


\begin{tabular}{|c|c|c|c|c|c|c|c|c|c|c|}
\hline Country & Year & Region & $\theta$ & $\mu$ & $\mu_{o}$ & $\lambda$ & 1 & 2 & 3 & 4 \\
\hline $\mathrm{COG}$ & 2005 & SSA & 0.45 & 0.32 & 1.00 & 1.00 & 2.78 & 2.78 & 3.35 & 3.35 \\
\hline CRI & 2011 & LAC & 0.92 & 0.45 & 0.56 & 0.62 & 4.52 & 20.08 & 5.14 & 21.94 \\
\hline $\mathrm{CIV}$ & 2002 & SSA & 0.48 & 0.63 & 0.27 & 0.91 & 6.78 & 10.40 & 7.46 & 11.40 \\
\hline HRV & 2011 & $\mathrm{EU}$ & 0.98 & 0.51 & 0.44 & 0.84 & 3.93 & 10.53 & 4.45 & 11.63 \\
\hline CYP & 2011 & $\mathrm{EU}$ & 1.00 & 0.22 & 0.30 & 0.91 & 6.73 & 10.31 & 7.55 & 11.43 \\
\hline DJI & 1996 & MENA & 0.81 & 0.68 & 1.00 & 0.55 & 1.78 & 21.67 & 2.12 & 23.63 \\
\hline DOM & 2001 & $\mathrm{LAC}$ & 0.80 & 0.53 & 0.22 & 0.70 & 5.74 & 17.58 & 6.35 & 19.18 \\
\hline DMA & 2010 & LAC & 0.56 & 0.55 & 0.00 & 0.91 & 9.63 & 12.88 & 10.53 & 14.06 \\
\hline $\mathrm{ECU}$ & 2011 & LAC & 0.73 & 0.44 & 0.97 & 0.64 & 3.25 & 18.45 & 3.86 & 20.26 \\
\hline EGY & 2011 & MENA & 1.00 & 0.17 & 0.83 & 0.25 & 6.06 & 36.34 & 7.17 & 39.22 \\
\hline SLV & 2011 & LAC & 0.83 & 0.59 & 1.00 & 0.71 & 2.34 & 14.86 & 2.79 & 16.36 \\
\hline ETH & 2005 & SSA & 0.47 & 0.25 & 0.25 & 1.00 & 14.79 & 14.79 & 16.21 & 16.21 \\
\hline FJI & 2008 & EAP & 0.79 & 0.57 & 0.00 & 0.52 & 6.31 & 25.52 & 6.91 & 27.66 \\
\hline GAB & 2005 & SSA & 0.61 & 0.55 & 1.00 & 0.72 & 2.14 & 14.30 & 2.56 & 15.75 \\
\hline GEO & 2010 & $\mathrm{CA}$ & 0.60 & 0.26 & 0.40 & 1.00 & 10.57 & 10.57 & 11.72 & 11.72 \\
\hline GHA & 2010 & SSA & 0.41 & 0.74 & 1.00 & 1.00 & 0.91 & 0.91 & 1.09 & 1.09 \\
\hline GRD & 1998 & LAC & 0.94 & 0.62 & 0.74 & 0.68 & 2.66 & 16.41 & 3.08 & 17.98 \\
\hline GTM & 2004 & LAC & 0.78 & 0.45 & 1.00 & 0.54 & 3.06 & 23.03 & 3.67 & 25.14 \\
\hline HND & 2010 & LAC & 0.67 & 0.69 & 1.00 & 0.57 & 1.51 & 20.48 & 1.80 & 22.34 \\
\hline HKG & 2011 & EAP & 1.00 & 0.32 & 0.06 & 0.92 & 6.08 & 9.20 & 6.68 & 10.08 \\
\hline IND & 2010 & $\mathrm{SA}$ & 0.32 & 0.33 & 0.60 & 0.42 & 9.33 & 30.63 & 10.35 & 33.15 \\
\hline IDN & 2009 & EAP & 0.48 & 0.34 & 0.43 & 0.76 & 10.42 & 18.99 & 11.52 & 20.75 \\
\hline IRN & 2008 & MENA & 0.71 & 0.15 & 0.51 & 0.23 & 9.83 & 38.14 & 11.02 & 41.05 \\
\hline JAM & 2011 & LAC & 0.63 & 0.62 & 0.16 & 0.86 & 6.38 & 11.92 & 7.02 & 13.04 \\
\hline KAZ & 2011 & $\mathrm{CA}$ & 0.79 & 0.69 & 1.00 & 0.95 & 1.66 & 3.72 & 1.98 & 4.23 \\
\hline KWT & 2011 & MENA & 1.00 & 0.81 & 0.00 & 0.50 & 1.55 & 23.95 & 1.71 & 25.99 \\
\hline KGZ & 2006 & $\mathrm{CA}$ & 0.67 & 0.44 & 0.44 & 0.81 & 7.04 & 14.38 & 7.84 & 15.79 \\
\hline LAO & 2005 & EAP & 0.44 & 0.44 & 0.04 & 1.00 & 13.83 & 13.83 & 15.10 & 15.10 \\
\hline LVA & 2011 & $\mathrm{EU}$ & 1.00 & 0.49 & 0.32 & 1.00 & 4.05 & 4.05 & 4.55 & 4.55 \\
\hline LBN & 2007 & MENA & 0.81 & 0.14 & 0.21 & 0.37 & 11.07 & 32.92 & 12.22 & 35.55 \\
\hline LSO & 1999 & SSA & 0.27 & 1.00 & 0.78 & 0.78 & 0.00 & 9.97 & 0.00 & 10.90 \\
\hline LBR & 2010 & $\mathrm{SSA}$ & 0.45 & 0.77 & 1.00 & 1.00 & 0.86 & 0.86 & 1.02 & 1.02 \\
\hline LTU & 2011 & $\mathrm{EU}$ & 1.00 & 0.39 & 0.41 & 1.00 & 4.86 & 4.86 & 5.50 & 5.50 \\
\hline MAC & 2011 & EAP & 1.00 & 0.33 & 0.06 & 0.97 & 5.94 & 6.93 & 6.53 & 7.62 \\
\hline MKD & 2011 & $\mathrm{EU}$ & 0.95 & 0.50 & 0.00 & 0.67 & 4.95 & 18.26 & 5.43 & 19.87 \\
\hline
\end{tabular}




\begin{tabular}{|c|c|c|c|c|c|c|c|c|c|c|}
\hline Country & Year & Region & $\theta$ & $\mu$ & $\mu_{o}$ & $\lambda$ & 1 & 2 & 3 & 4 \\
\hline MDG & 2010 & SSA & 0.48 & 0.32 & 0.28 & 1.00 & 12.75 & 12.75 & 14.00 & 14.00 \\
\hline MWI & 1987 & SSA & 0.29 & 0.08 & 1.00 & 1.00 & 3.01 & 3.01 & 3.65 & 3.65 \\
\hline MYS & 2011 & EAP & 0.95 & 0.35 & 0.30 & 0.57 & 5.96 & 23.13 & 6.67 & 25.18 \\
\hline MDV & 2006 & $\mathrm{SA}$ & 1.00 & 0.24 & 1.00 & 0.58 & 5.14 & 22.17 & 6.19 & 24.37 \\
\hline MLI & 2006 & SSA & 0.51 & 0.45 & 0.76 & 0.88 & 4.84 & 9.79 & 5.49 & 10.87 \\
\hline MLT & 2011 & $\mathrm{EU}$ & 1.00 & 0.34 & 0.00 & 0.54 & 5.94 & 24.28 & 6.51 & 26.33 \\
\hline MUS & 2011 & SSA & 0.99 & 0.29 & 0.27 & 0.56 & 6.05 & 23.44 & 6.76 & 25.50 \\
\hline MDA & 2011 & $\mathrm{EU}$ & 0.77 & 0.50 & 0.25 & 1.00 & 6.37 & 6.37 & 7.05 & 7.05 \\
\hline MNG & 2011 & EAP & 0.84 & 0.49 & 0.33 & 0.95 & 5.55 & 7.61 & 6.19 & 8.42 \\
\hline MAR & 2008 & MENA & 0.75 & 0.24 & 0.29 & 0.42 & 10.08 & 30.80 & 11.16 & 33.33 \\
\hline MOZ & 2003 & SSA & 0.35 & 0.18 & 0.49 & 1.00 & 13.84 & 13.84 & 15.27 & 15.27 \\
\hline NAM & 2011 & SSA & 0.92 & 0.63 & 1.00 & 0.82 & 2.20 & 9.91 & 2.63 & 11.01 \\
\hline NPL & 2001 & $\mathrm{SA}$ & 0.44 & 0.97 & 1.00 & 0.77 & 0.12 & 10.81 & 0.14 & 11.82 \\
\hline NER & 2005 & SSA & 0.20 & 0.50 & 1.00 & 0.38 & 1.11 & 28.87 & 1.33 & 31.26 \\
\hline OMN & 2010 & MENA & 1.00 & 0.59 & 1.71 & 0.20 & 1.99 & 37.37 & 2.61 & 40.27 \\
\hline PAK & 2008 & $\mathrm{SA}$ & 0.66 & 0.02 & 0.28 & 0.34 & 15.49 & 35.68 & 17.07 & 38.48 \\
\hline PAN & 2011 & LAC & 0.78 & 0.60 & 0.03 & 0.67 & 5.76 & 18.90 & 6.32 & 20.57 \\
\hline PRY & 2010 & LAC & 0.77 & 0.45 & 1.00 & 0.61 & 3.07 & 19.58 & 3.68 & 21.47 \\
\hline PER & 2011 & LAC & 0.72 & 0.39 & 0.90 & 0.80 & 4.03 & 12.20 & 4.73 & 13.56 \\
\hline PHL & 2008 & EAP & 0.74 & 0.46 & 0.66 & 0.66 & 4.86 & 18.91 & 5.52 & 20.70 \\
\hline QAT & 2004 & MENA & 1.00 & 0.12 & 0.00 & 0.17 & 8.50 & 39.77 & 9.30 & 42.72 \\
\hline $\mathrm{ROM}$ & 2011 & $\mathrm{EU}$ & 0.87 & 0.43 & 0.11 & 0.87 & 6.64 & 11.53 & 7.32 & 12.63 \\
\hline RUS & 2008 & $\mathrm{EU}$ & 1.00 & 0.61 & 0.55 & 0.96 & 2.84 & 4.39 & 3.25 & 4.94 \\
\hline RWA & 1996 & SSA & 0.45 & 0.81 & 1.00 & 1.00 & 0.72 & 0.72 & 0.85 & 0.85 \\
\hline LCA & 2000 & LAC & 0.77 & 0.42 & 0.51 & 0.87 & 6.03 & 11.24 & 6.77 & 12.43 \\
\hline STP & 1991 & SSA & 0.85 & 0.24 & 0.97 & 0.50 & 4.86 & 25.46 & 5.83 & 27.81 \\
\hline SAU & 1992 & MENA & 1.00 & 0.10 & 0.11 & 0.13 & 8.49 & 41.66 & 9.37 & 44.69 \\
\hline SEN & 2011 & SSA & 0.76 & 0.20 & 1.00 & 0.75 & 4.62 & 14.83 & 5.58 & 16.53 \\
\hline $\mathrm{SRB}$ & 2011 & $\mathrm{EU}$ & 0.87 & 0.52 & 0.00 & 0.77 & 5.85 & 14.85 & 6.41 & 16.20 \\
\hline SGP & 2011 & EAP & 1.00 & 0.47 & 0.08 & 0.79 & 4.51 & 13.28 & 4.97 & 14.52 \\
\hline ZAF & 2011 & SSA & 1.00 & 0.37 & 0.86 & 0.77 & 4.33 & 13.71 & 5.11 & 15.23 \\
\hline LKA & 2011 & $\mathrm{SA}$ & 0.71 & 0.23 & 0.45 & 0.57 & 9.34 & 24.98 & 10.43 & 27.19 \\
\hline KNA & 2001 & $\mathrm{LAC}$ & 1.00 & 0.36 & 0.30 & 0.87 & 5.27 & 10.33 & 5.91 & 11.40 \\
\hline VCT & 2008 & $\mathrm{LAC}$ & 1.00 & 0.46 & 0.57 & 0.76 & 4.01 & 14.21 & 4.60 & 15.65 \\
\hline SUR & 1998 & LAC & 0.95 & 0.25 & 0.24 & 0.49 & 7.33 & 26.91 & 8.16 & 29.20 \\
\hline
\end{tabular}




\begin{tabular}{l|cc|cccc|cc|cc}
\hline Country & Year & Region & $\theta$ & $\mu$ & $\mu_{o}$ & $\lambda$ & 1 & 2 & 3 & 4 \\
\hline \hline SWZ & 1997 & SSA & 0.98 & 0.79 & 1.00 & 0.69 & 1.26 & 14.95 & 1.50 & 16.39 \\
SYR & 2011 & MENA & 0.73 & 0.21 & 0.03 & 0.18 & 13.13 & 40.49 & 14.35 & 43.47 \\
TJK & 2009 & CA & 0.52 & 0.18 & 0.69 & 0.87 & 8.68 & 13.55 & 9.80 & 15.04 \\
TZA & 2011 & SSA & 0.56 & 0.33 & 0.93 & 1.00 & 3.99 & 3.99 & 4.68 & 4.68 \\
THA & 2011 & EAP & 0.70 & 0.38 & 0.46 & 0.94 & 7.39 & 9.59 & 8.25 & 10.64 \\
TTO & 2005 & LAC & 0.96 & 0.50 & 0.24 & 0.68 & 4.40 & 17.61 & 4.90 & 19.22 \\
TUN & 1994 & MENA & 0.88 & 0.27 & 0.37 & 0.32 & 7.45 & 33.93 & 8.34 & 36.63 \\
UGA & 2003 & SSA & 0.33 & 0.49 & 0.53 & 1.00 & 7.92 & 7.92 & 8.76 & 8.76 \\
UKR & 2011 & EU & 0.96 & 0.62 & 0.96 & 0.95 & 2.41 & 4.70 & 2.86 & 5.36 \\
URY & 2010 & LAC & 0.89 & 0.47 & 0.58 & 0.88 & 4.45 & 9.52 & 5.06 & 10.57 \\
VEN & 2011 & LAC & 0.76 & 0.34 & 0.86 & 0.65 & 4.66 & 18.95 & 5.44 & 20.82 \\
VNM & 2004 & EAP & 0.52 & 0.43 & 0.30 & 1.00 & 9.90 & 9.90 & 10.90 & 10.90 \\
YEM & 2010 & MENA & 0.78 & 0.43 & 1.00 & 0.08 & 3.20 & 43.37 & 3.83 & 46.48 \\
ZMB & 2000 & SSA & 0.55 & 0.33 & 0.36 & 1.00 & 10.54 & 10.64 & 11.64 & 11.75 \\
ZWE & 2002 & SSA & 0.67 & 0.56 & 1.00 & 0.92 & 2.22 & 5.72 & 2.66 & 6.46
\end{tabular}

